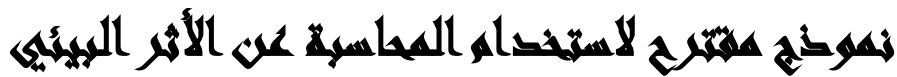

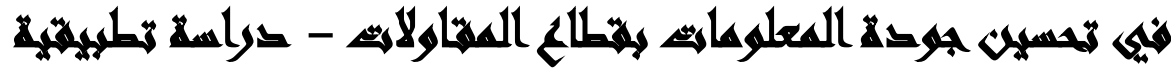

[11]

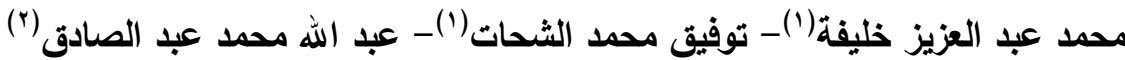

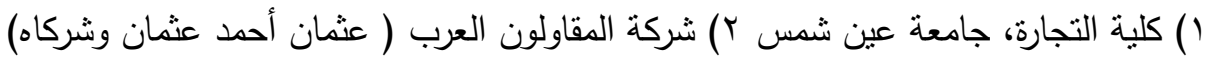

\section{المستخليه}

هدفت هذه الدراسة إلى إعداد نموذج لاستخدام المحاسبة عن الأثر البيئي لتحسين جودة

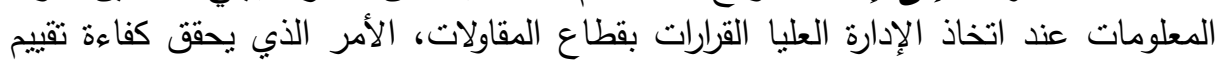

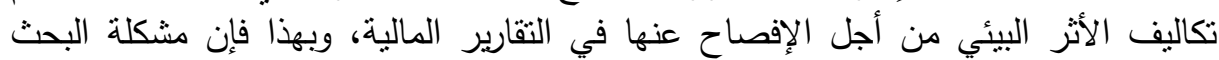

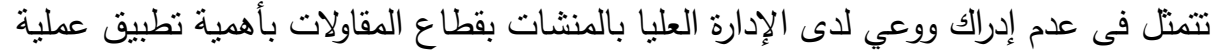

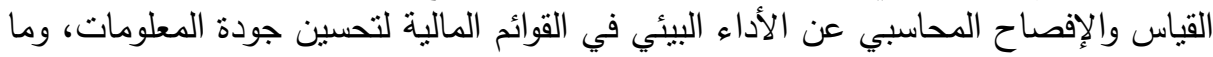

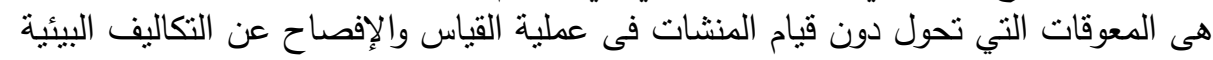

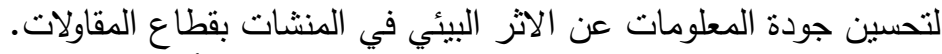

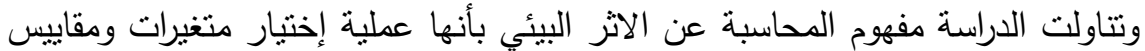

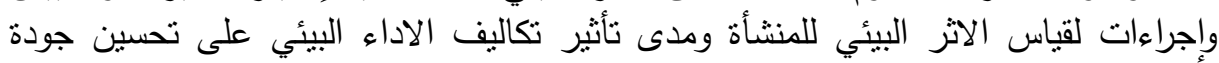

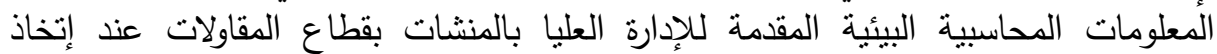

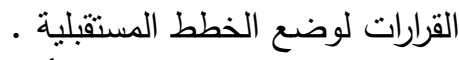

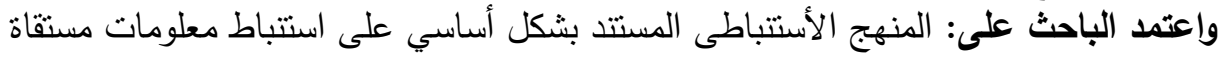

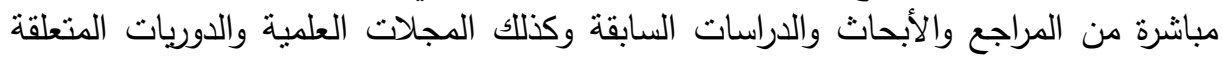

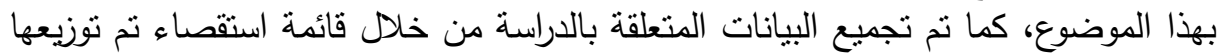

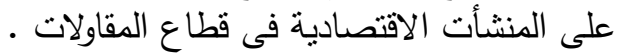

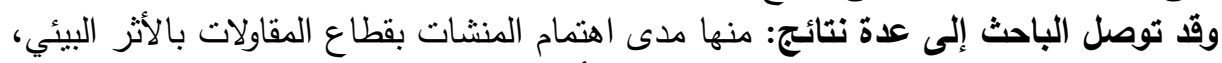

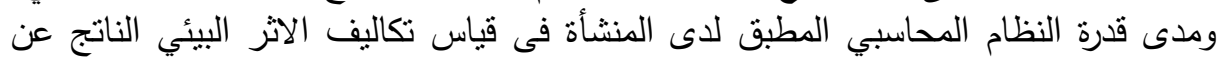
أنشطة المنشأة على البيئة المحيطة، ومدى أهمية تأثثير قياس وتحليل الثيل الأثر البيائي على جودة البيأي

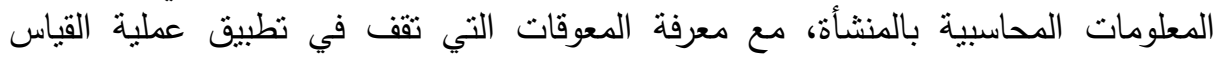
والإفصاح عن تكاليف الأثر البيئي في القوائم المالية للمنشات بقطاع المات المقاولات . 


\section{ll}

إن تفاقم المشكلات البيئية حول العالم، وما يترتب عليها من مخاطر تهدد كل الكائنات على السواء، مما التي يستوجب على المجتمع المشاركة الفعالة في مواجهة تلك المشكلات البيئية ، فلا يكاد يخلو اليوم محفل من محافل العلم، و لا دائرة من دوائر البحث على مستوى العالم من مناقثنة قضايا البيئة، بل أصبحت قضية البيئة شأناً إنسانياً عاماً تعقد من دن أجله

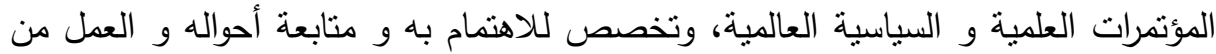

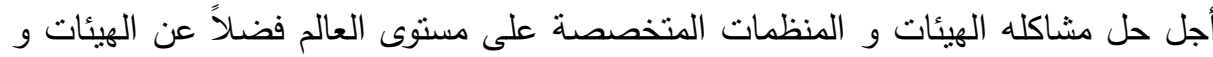
المنظمات ذات الطابع المحلي و الإقليمي ـ لذلك كان للمختصين بالعلوم المالية و المحاسبية دور في المساهمة في حل المشكلات البيئية ، باستحداثهم لأجندات و أنظمة مالية تختص الإنص

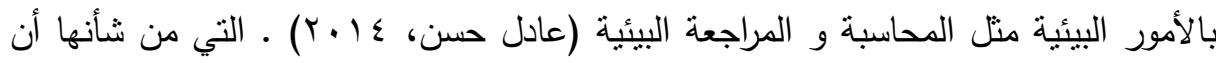

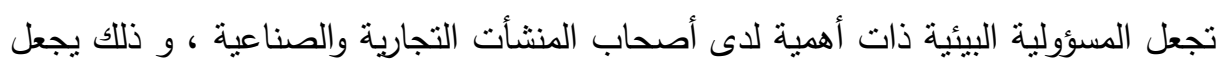
الخسائر البيئية الناتجة عن منتجات المنشأة ذات أثر سلبي على العوائد و الأرباح التي تجنيها المنشأة ـ وهذا من شأنه أن يجعل كل المنشأت الاقتصادية تسعى إلى الحفاظ على البيئة ومكونات النظام البيئي الآن أساسا من أسس النهضة و ولند التنمية الاقتصادية وذلك لان الحفاظ

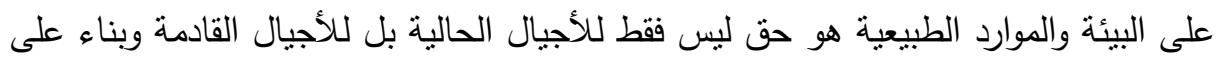

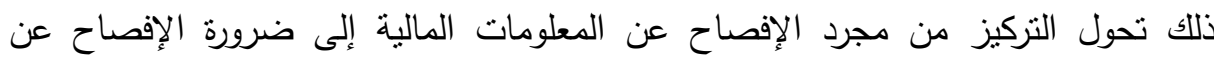
المعلومات الاجتماعية والبيئية من خلال التقارير والقوائم المالية السنوية (مهاوات لعبيدى،

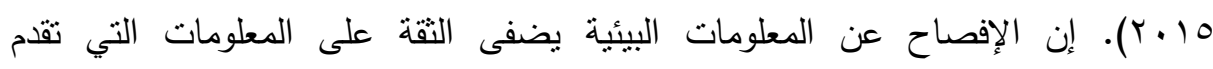
لمستخدمي القوائم المالية لنرشيد قراراتهم في ظل المنغيرات البيئية المعاصرة وضخامتها

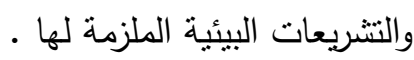

وإذا كان التطبيق الحالي للمحاسبة يقوم على مبدأ مقابلة الإيرادات بالتكاليف دون اخذ

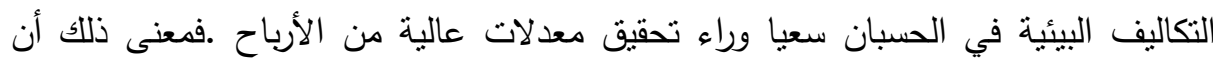
المحاسبة تكون قد ساهدت بصورة غير مبانشرة في إفساد البيئة نتيجة عدم إدخالها تكلفة الرقابة على التلوث والحد منة ضمن معادلة أرباحها وما يترتب على ذللك من أضعاف للتقة 
في البيانات والمعلومات التي تتضمنها تلك التقارير والقوائم الأمر الذي يقلل من الاعتماد على نتائج أعمال تلك المنشأت الاقتصادية كمؤشر لتقييم الأداء.

\section{القراسائ المريعية}

تضمنت الدراسة العديد من الدراسات المرجعية التي ناقشت و تتاولت موضوع الدراسة و فيما يلي أهم هذه الاراسات مرتبة ترتيبا زمنيا:

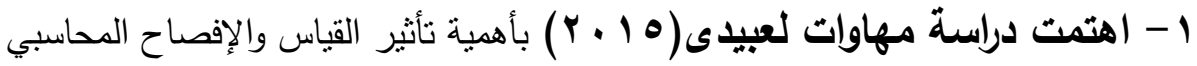
للتكاليف البيئية في القوائم المالية على تحسين الأداء البيئي إلا أن معظم المنشأت ترفض

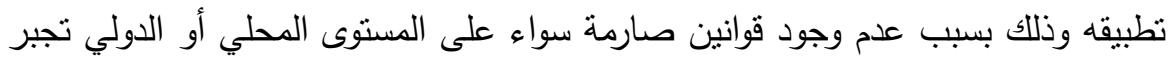

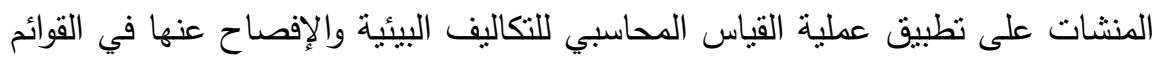
والتقارير المالية وذلك من خلال التحليل الإحصائي للاراسة ـ وتوصلت الدراسة بضرورة أن تعمل المنظمات والهيئات العلمية المحاسبية الدولية والوطنية على القيام بالدور المطلوب منها في ما يخص حماية البيئة، وذلك عن طريق إصدار معايير محاسبية

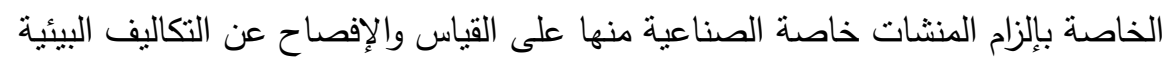
في تقاريرها المالية وذلك بغرض تحسين الأداء البيئي.

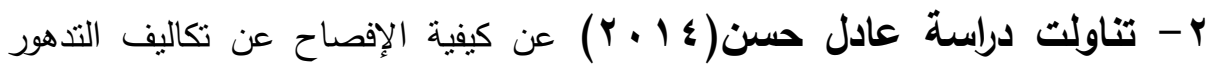
البيئي، وما هي البنود الواجب الإفصاح عنها، وما هى عناصر الإفصاح البيئي الكامل، وكيف يمكن أن يؤدى ذلك إلى تحسين نتائج الأعمال وترشيد القرارات الإدارية المختلفة.

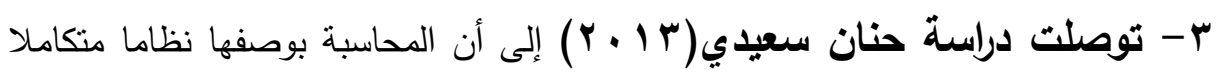
للمعلومات، في علاقة متبادلة مع البيئة، فهي لا تتأثر فقط بالبيئة وإنما نؤثر فيها أيضا

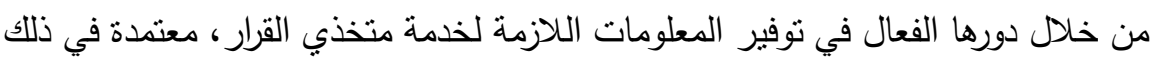
على ركيزتين أساسيتين هما القياس والإفصاح المحاسبي للمعلومات المحاسبية المتعلقة بالأنشطة البيئية الني تؤديها المنشات الصناعية والواردة في قوائمها المالية، كما توصلت الدراسة إلى القياس والإفصاح المحاسبي عن التأثيرات البيئية يعتبر ركن من أركانية

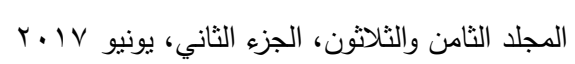


المحاسبة البيئية ومؤشرا ذو اتجاهين، وما إذا كانت المنشات الصناعية مدركة للقضايا التي تؤثر في بقاءها واستمرارها من جهة، ويمثل مقياسا لمستخدمي القوائم المالية للوقوف

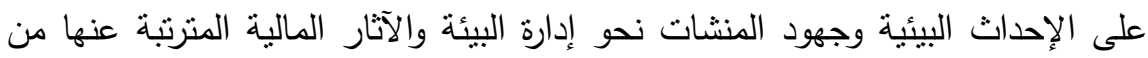

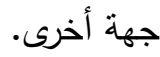

ع - تناولت دراسة مجدي شكري فوزي(11 + ب) مفهوم التقييم الاقتصادي لتكلفة التدهور البيئي في قطاع المقاولات، حيث تقوم المنشات بقطاع المقاولات بإبرام العقود مع عملائها، وكل عقد تبرمه المنشأة للقيام بعمل إنشائي مع أحد العملاء يعتبر أمراً إنتاجياً مستقلاً مما يترتب عليه مشاكل محاسبية كثيرة سواء كانت تكلفة التدهور البيئي ذات طبيعة اقتصادية، أو مرتبطة بالبيئة غير النظيفة، ومنها عدم ملائمة أساليب إدارة المخلفات، والثعور بالألم والمعاناة من الإصابات والأمراض الناجمة عن التلوث البيئي الأمر الذي أدى إلى تدهور الموارد الطبيعية.

ه- توصلت دراسة (Jaikumar, Karpagam, and Thiyagarajan,2013)

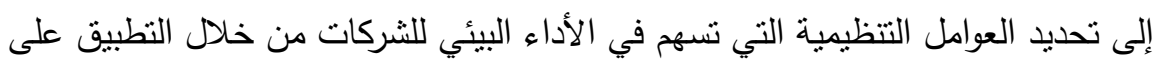
عينة من (r) شركة صناعية هندية . حيث حددت الدراسة تطبيق المحاسبة البيئية كجزء

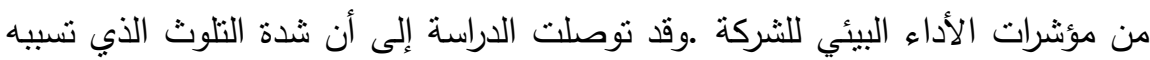

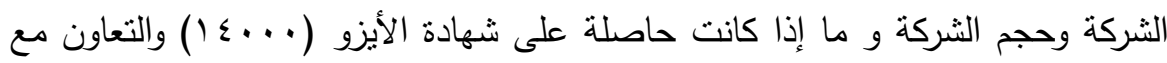

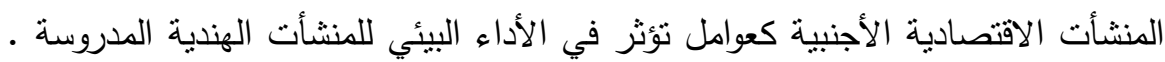

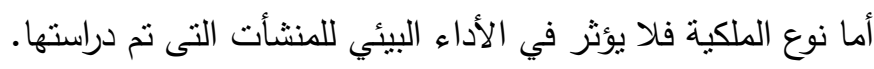

צ- تناولت دراسة (Patricia Stanton,2012) مفهوم الإفصاح البيئي في تايلاند من خلال معرفة مستوى الإفصاح عن المعلومات البيئية الواردة في التقارير السنوية للثركات المدرجة في البورصة التايلاندية بدراسة تطبيقية تمنلت في فحص التقارير المالية لسنة

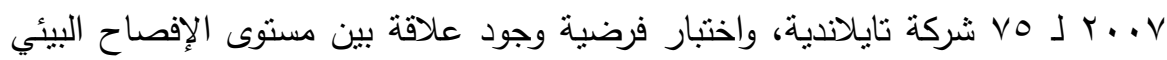

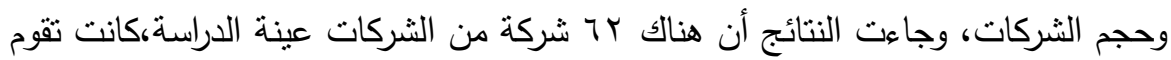


بالإفصاح عن معلوماتها البيئية، بنسبة أكبر من تلك الناشطة في صناعات أخرى، ووجود علاقة إيجابية وطردية بين الإفصاح البيئي وحجم الثركات.

- Vتاولت دراسة (Teresa Cristina,2009) دوافع تبنى الإدارة لمحاسبة المسئولية البيئية وذلك من خلال الدراسة التطبيقية التي تمت على شركة الاسمنت البرتغالية (secil)

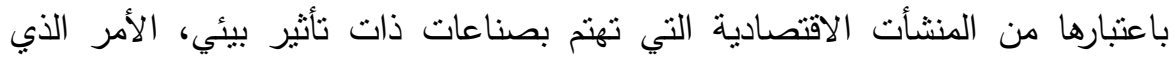

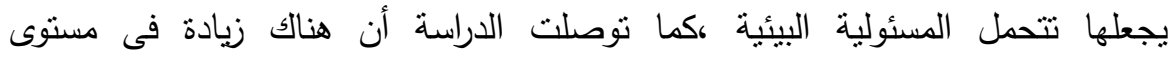
المعلومات البيئية والاجتماعية المفصح عنها فى النقارير السنوية خلال السنوات الأخيرة، مع وجود علاقة قوية بين سياسات الإفصاح البيئي واهتمام المجتمع وأصحاب المصائه

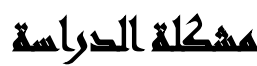

تعثبر المحاسبة عن الأثر البيئي أحدث مراحل النطور المحاسبي ولقد نشأ هذا النطور الحديث نتيجة للازدياد المنفرد في حجم قرارات المنشآت التي لها تأثثرات مالية وبيئية واسعة التئ النطاق، مما زاد اهتمام الفكر المحاسبي بالمحاسبة عن الأثر البيئي باعتبارها تمثل التوسع تئئي

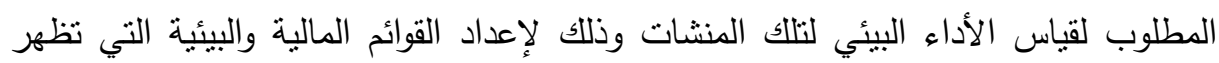
مدى وفاء هذه المنشات بمسئولياتها المنمثلة في الأنشطة المالية والبيئية وهي بصدد اتخاذ القرارات المستقبلية الخاصة بالأنشطة الاقتصادية بما بحقق التوافق بين مصلحتها ومصلحة

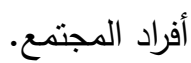

وقد أجمعت معظم الدراسات السابقة السابق الإشارة إليها والآراء علي أهمية تطبيق

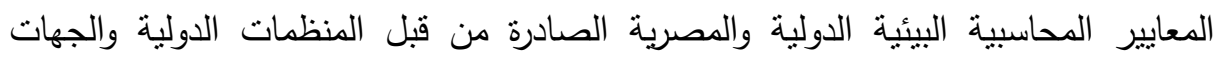
الحكومية وذلك لالزام المنشات الاقتصادية بزيادة مستوى الإفصاح عن أدائها البيئي في

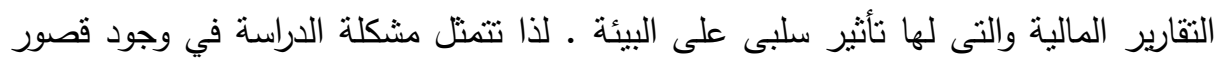
في نظم وأساليب القياس والرقابة على البيانات الخاصة الأداء البيئي في السجلات البئ المحاسبية

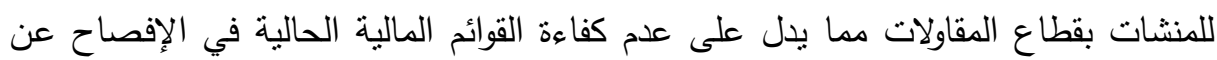
المعلومات المحاسبية ذات العلاقة بالأثز البيئي بالأخص حساب تكاليف الأثر البيئي وذلك اللكات

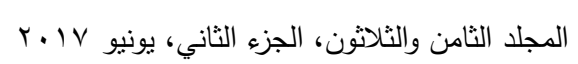


لإدراجها ضمن بنود التكاليف الكلية مما يؤثر على جودة المعلومات المحاسبية عن الأثر

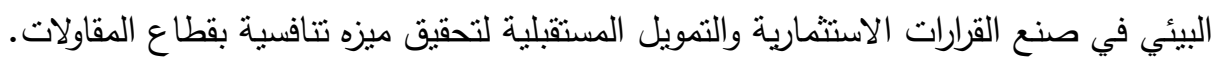

\section{أسئلة التوراهة}

تسعي الدراسة الي الأجابة علي التساؤلات الرئيسة التالية:

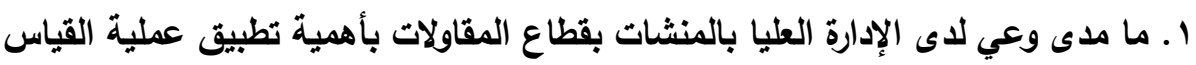

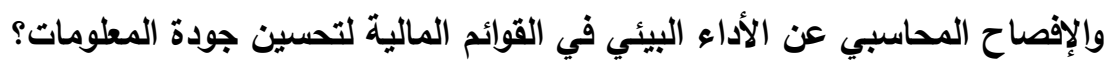
يندرج تحت التساؤل الاول أسئلة فرعية كما يلى الإدي

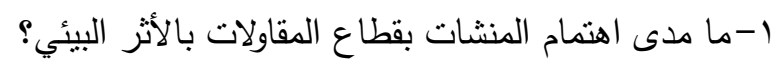

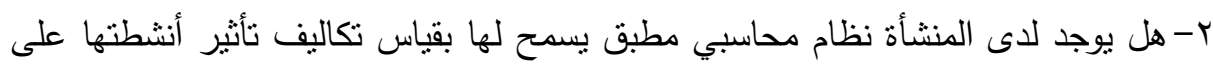
البيئة المحيطة ؟ بوجي اله

r-ما مدى أهمية البيانات الخاصة بالأثر البيئي لكل إدارة فى المنشات بقطاع المقاولات؟

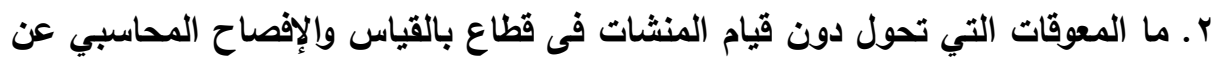
اثر الأداء البيئي؟

يندرج تحت التساؤل الثانى سؤال فرعى كما يلى: ماهى العوامل المطلوبة لتطبيق عملية القياس والإفصاح المحاسبي عن الأثر البيئي التي يمكن الاعتماد عليه في اتخاذئ التهاذ القرارات بالمنشات بقطاع المقاولات؟ r. ما أثر للقياس والإفصاح عن التكاليف البيئية في تحسين جودة المعلومات عن الأداء البيئي في المنشات بقطاع المقاولات؟

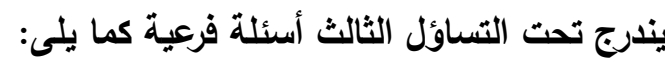
ا-ما أثز استخدام القياس والإفصاح المحاسبي الأداء البيئي في تحسين جودة المعلومات لادى متخذي القرارات في المنشات بقطاع المقاولات؟ ץ-ما مدى استخدام المعلومات عن الأثر البيئي من قبل الإدارة العليا عند اتخاذهم القرارات الإدارية؟ 
r-هل يساهم مساهمة الإفصاح الدحاسبي عن تكاليف الأثر الييئي فى تحقيق ميزه تتافسية لل المنشات في قطاع المقاولات؟

\section{هزوخه التواسلا}

تعتمد هذه الدراسة علي الفروض الآتية: الفرض الأول HOI: لا توجد علاقة جوهرية بين الاعتماد على المعايير المحاسبية في ضوء الأبعاد البيئية المؤثرة عند إعداد القوائم المالية وتحسين جودة المعلومات المحاسبية. الفرض الثاني HOr: لا توجد علاقة جوهرية بين المعوقات والعوامل المطلوبة لنطبيق القياس والإفصاح عن أثز الأداء البيئي فى القوائم المالية لدى منثات قطاع المقاولات وأثنر استخدام القياس والإفصاح في تحسين جودة المعلومات. الفرض الثالث HOr: لا نوجد علاقة جوهرية بين عملية قياس ومعالجة بيانات تكاليف الأثر البيئي ومساهمة الإفصاح المحاسبي فى تحقيق ميزة تنافسية للمنشآت في قطاع المقاولات.

\section{أهساهثم الصواسها}

\section{تسعي الاراسة الي تحقيق الأهداف الأتية: \\ ا ـ توضيح مفهوم وأهداف الاثر البيئي وعلاقته بالنظام المحاسبى.}

r. تحديد مدى إعنماد ادارة المنشأت بقطاع المقاولات على قياس الاثر البيئي فى عملية

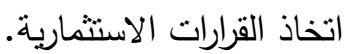

r. تحديد اساليب وطرق القياس المحاسبي للتأثيرات البيئية، وكيفية الإفصاح عنها في التقارير المالية، والمعوقات التي تعترض نطبيقهما في قطاع المقاولات.

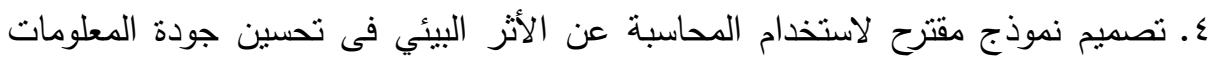
يساعد المنشات بقطاع المقاولات.

ه. اسنطلاع أراء معدى التقارير المالية وبعض متخذى القرارات فى المنشأت بقطاع المقاولات حول اثر القياس والافصاح عن الاداء البيئي فى ترشيد القرارات الاستثمارية المستقلية من اجل تحقيق ميزه تتافسية بقطاع المقاولات. 


\section{أهمري القواسما}

تتبع أهمية الدراسة من الأهمية المتزايدة للمسؤولية البيئية للمنشات في تناول القياس والإفصاح المحاسبي عن تكاليف الاثر البيئي، ويرجع هذا الاهتمام الى العديد من الأسباب

$$
\text { والتى من أهمها: }
$$

ا. التعرف على مدى كفاءة النظام المحاسبي للمنشأة للحصول على معلومات عن نكاليف الاثر البيئي للمنشأة ومدى تأثنرها على باقى تكاليف المنشأة، مع التعرف على مدى كفاءة

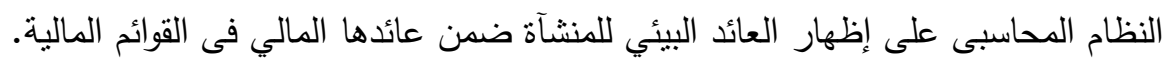
r. أهميه قياس الاثر البيئى للمنشأة حيث يؤدى الى تقييم نظم الإدارة البيئية ومدى رقابة لفئي المنشأة لتكاليف الاثر البيئى ومدى تحقيقها للأهداف المرسومة، حيث تتكبد المنشاة أعباء

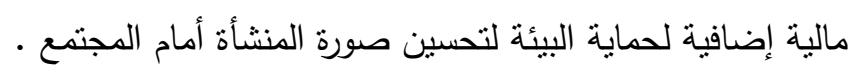
r. تزايد اهتمام الهيئات والمنظمات المحاسبية بإصدار المعايير والنشرات الخاصة بالاحداث البيئية والتي أضفت المصداقية للمعلومات التي يجب الإفصاح عنها فى القوائم المالية .

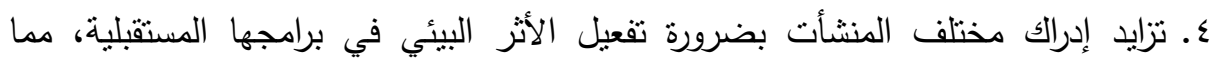
يساعدها على تحقيق أهدافها وأهداف المجتمع في التتمية المستدامة، ويضمن استمرارها

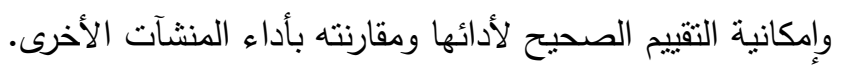

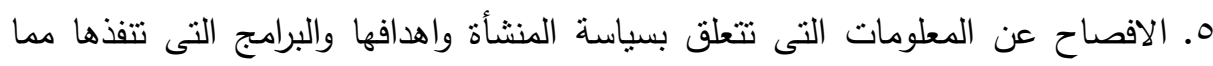

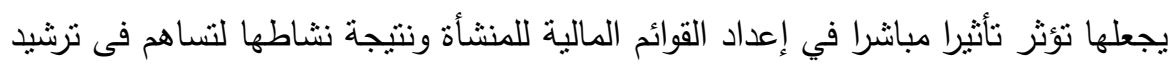

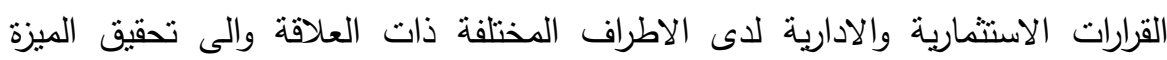
التنافسية للمنشأت الاقتصادية.

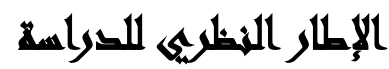

\section{أولاً: الإطار العام لمفهوم المحاسبة عن الاثر البيئي:}

يعتبر تقييم الاثر البيئي وسيلة فعالة لمساعدة صانعي القرار وذلك من خلاد عملية المراجعة والتدقيق وادخال عناصر البيئة واشراكها في صنع القرار وصولاً الى التتمية 
المستدامة للاستراتيجية البيئية المبنية على الاداء الجيد للخطط والبرامج السياسات. والمقصود بمفهوم تقيبم الآثر البيئى هو تقييم الأثر للمشاريع ودراسة الجوانب السلبية ومحاولة التخفيف من الآثار وليس وقف المشاريع بلضمان إدخال الأبعاد والعناصر البيئية في عملية التخطيط لهابل

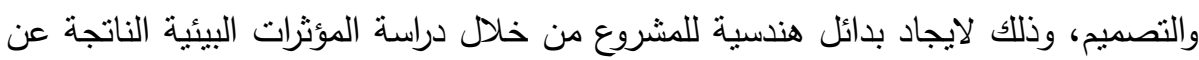
المشروع.

ويعتبر تعرف وزارة البيئة اليابانية تجسيدا لدور المحاسبة عن الاثر البيئي فى القياس المحاسبى حيث عرفتها على أنها نظام بعمل على تحديد التكاليف والمنافع فى أنشطة الحماية

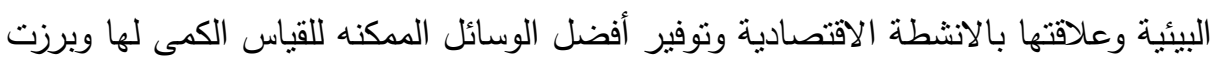
اتجاهات منباينه فى تحديد الانشطة البيئية وتبويبها فى مجموعات متجانسة وذللك من خلال

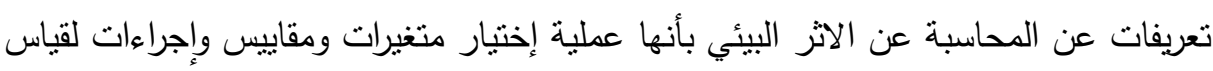
الاداء البيئي للمنشأة والافصاح عن النتائج الى الاطراف المعنية فى المجتمع سواء كانت هذه الهن

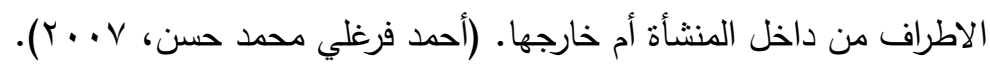

1 - أهداف المحاسبة عن الاثر البيئي: تتمثل الأهداف الأساسية للمحاسبة عن الاثر البيئي

$$
\text { فيما يلي: }
$$

أ- تحديد وقياس صافي المساهمة البيئية للمنشأة التي لا تشنمل فقط على عناصر التكاليف

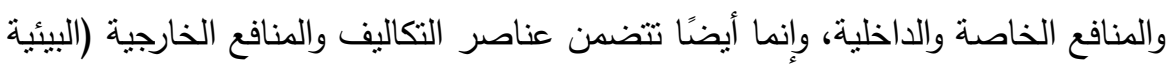

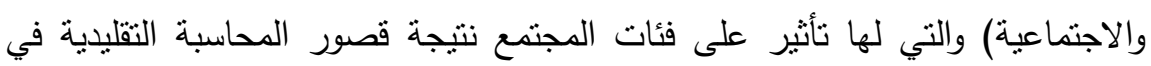

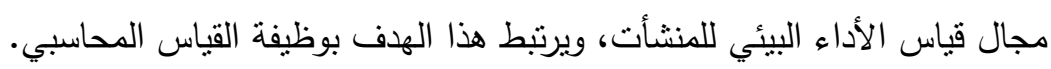

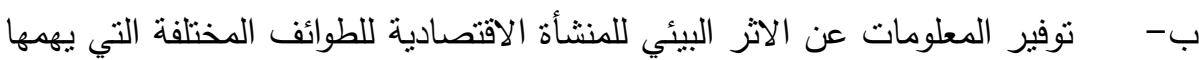
هذا الاثر والتي تساعدهم في تقييم خطة تنفيذ الأداء البيئي.

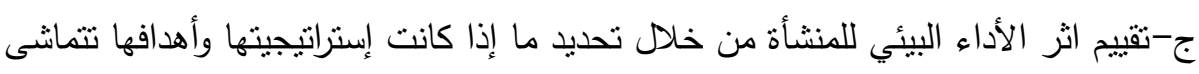
مع الأولويات البيئية من جهة، ومع طموح المنشأة للأفراد بتحقيق نسبة معقولة من الأرباح

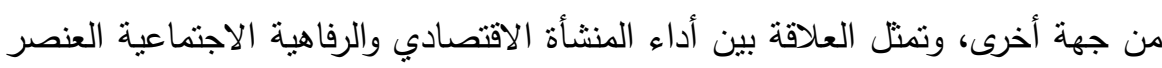

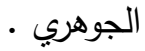

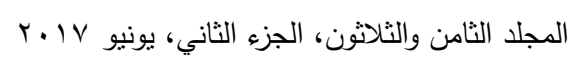


د- الإفصاح عن الأنشطة التي تقوم بها المنشأت لها آثار بيئية، ويظهر هذا الهدف ضرورة توفير البيانات الملائمة عن الأداء البيئي للمنشأة، ومدى مساهمتها في تحقيق الأهداف

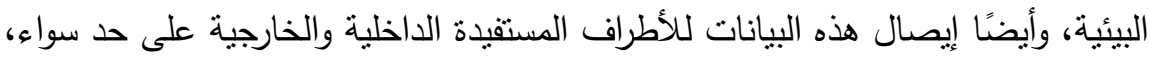

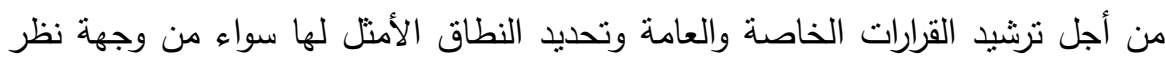
المجتمع المستخدم أو من وجهة نظر ويرتبط هذا الهدف بوظيفة الاتصال المحاسبي. هـ-المساهمة في تقليل الآثار السلبية الناتجة عن النشاط الصناعى للمنشأت الاقتصادية، مما ها

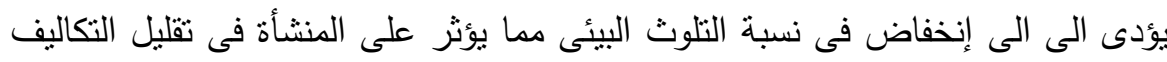
البيئية التي تدفعها المنشأة أو منعها، وتحسين الأداء البيئي وتحقيق الميزة التنافية بئ بئن المنشأت . المانه

r- أهمية القياس المحاسبي للأثر البيئي: يعتبر القياس المحاسبي ذلك القياس الكمي

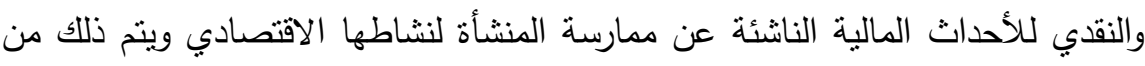
خلال تجميع وتبويب وتحليل والتسجيل لهذه العمليات الاقتصادية حتى ينم إعداد الحسابات الختامية للنشاط في نهاية الفترة المالية. ويمكن أن نوضح بأن التقيبيم هو تحديد

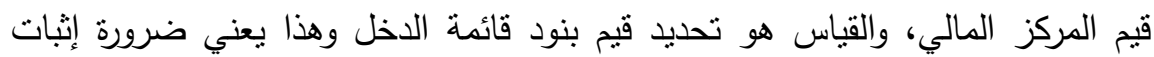

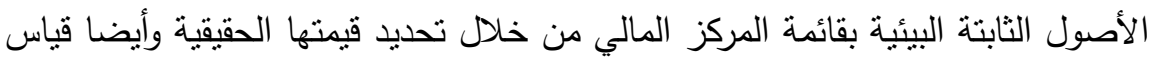
نتيجة النشاط من خلا مقابلة الإيرادات بالمصروفات ومنها البيئي حيث أن العطليات البيئية يتزتب عليها تكاليف بيئية لإزالة تلك التأثثرات التي تحدثها المنشأة نتيجة ممارسة باتهات

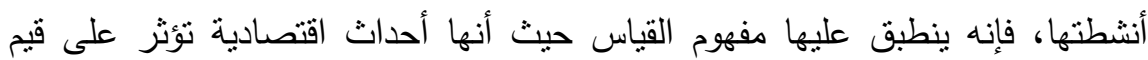

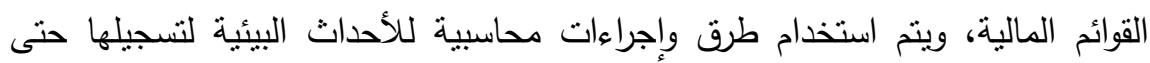

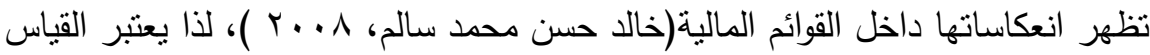
البيئي هو ترجمة لنشاط المنشأة في البيئة بشكل كمي أو مالي يمكن بواسطتها الحصول على معلومات بيئية تفسر للمستخدمين القوائم المالية المنشأة. 
ץ- أساليب وطرق القياس المحاسبي البيئي: تكمن الصعوبة الأساسية في القياس المحاسبي

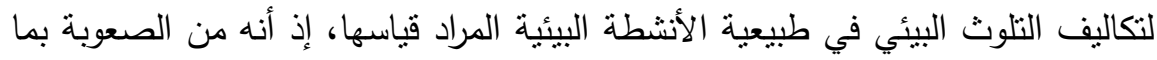

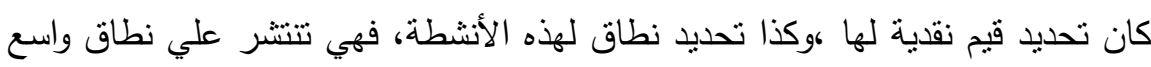

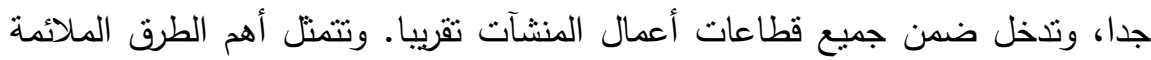

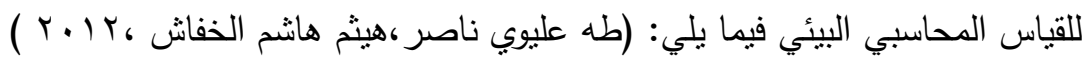

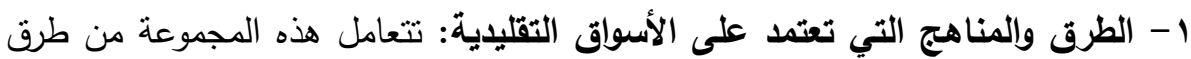
القياس والتصميم على معطيات و مؤشرات السوق من خلال الطرق التالية:

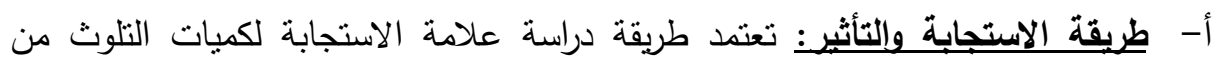
الطرق غير المباشرة للقياس، حيث تعتمد على على وجود علاقة سبيية بين التلوث والأثر الذي يحدثه على الثروة البشرية والمادية والطبيعية فعلى سبيل المثال يمكن قياس نكاليف المرض الناتج عن التلوث من خلال قياس التكاليف المباشرة وغير المباشرة كآلاتي: فالتكاليف المباشرة: تشمل تكاليف علاج المرض الناتج عن التلوث، والمتمنلة في تكاليف المستشفى والرعاية الصحية. • أما التكاليف غير المباشرة :تشمل التكاليف المتعلقة بعجز الثخص المصاب عن العمل

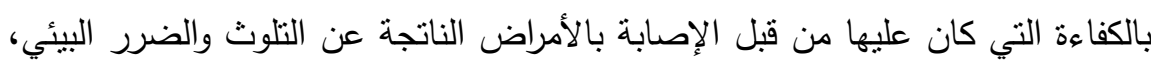

$$
\text { ويمكن قياسها بانخفاض الإنتاجية. }
$$

ب- طريقة التأثير على الإنتاجية: تقوم هذه الطريقة على أساس ملاحظة التغير المادي على بلى

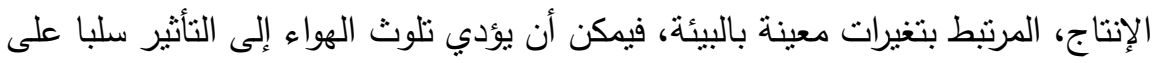

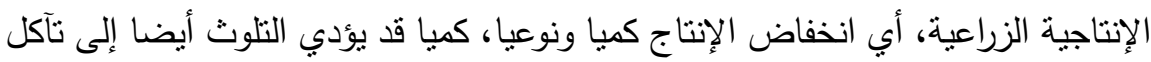

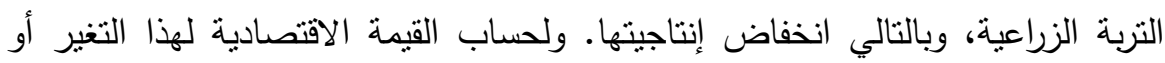
الانخفاض في الإنتاجية الزراعية كميا في سعر الطن المباع.، كما توضحه المعادلة

القيمة الاقتصادية للتغير = مقدار الانخفاض في الإنتاجية الزراعية كمياX سعر الطن

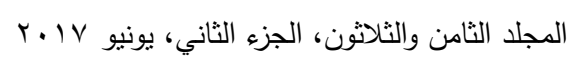


ت - طريقة تكاليف الإحلال: ينتج عن التلوث وتدهور البيئة، إضرار بالأصول والموارد

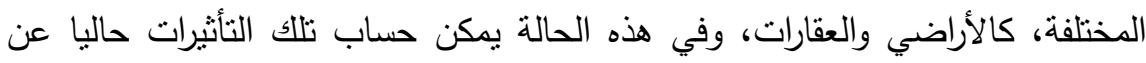
طريق حساب تكاليف إحلال الأصل المتأثز أو المتضرر، أو تكاليف إرجاعه إلى حالته الأصلية التي كان عليها، ومن الصعوبات التي يمكن أن تصاحب نطبيق هذه الطريقة، إذا إذا كانت الأصول المتأثزة هي أصول ذات قيمة ومن تاريخية أو نقافية.

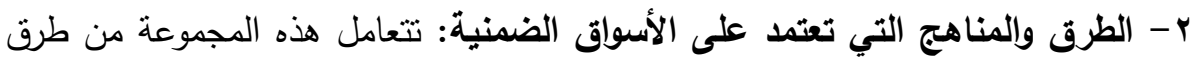

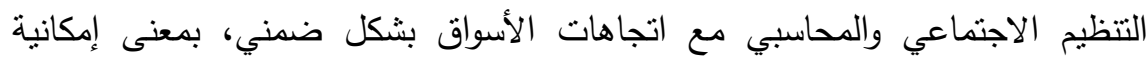

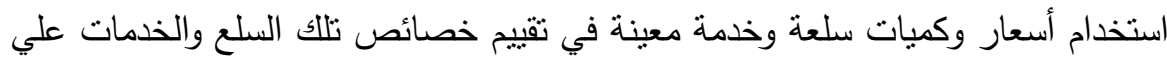
الرغم من أن طريقة تبادلها تكون بشكل مباشر في الأسواق ومن أمنلة تلك الطرق:

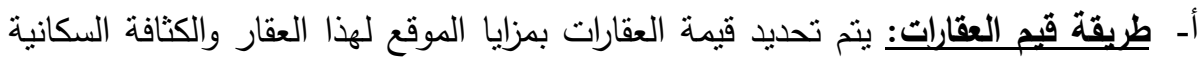
والمنظر الذي يطيل عليه ونوعية الهواء، ويمثل سعر العقار محصلة القيم السابقة

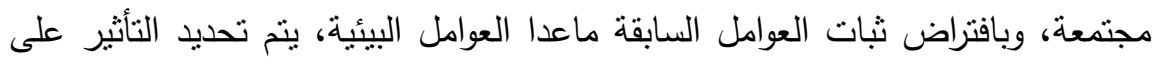

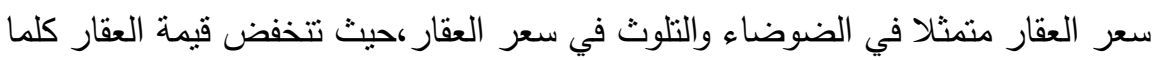
زادت الثنأثيرات البيئية السلبية المحيطة به. ب-طريقة اختلاف الأجوف: تتثابه هذه الطريقة مع طريقة قيمة العقارات في أسسيها النظرية، ولكن تختلف عنها في تحديد مدى القبول بزيادة الأجور والتعويض، لمن تضررت صحته نتيجة التلوث مقابل زيادة في الأجر ، ومقارنة هذه الأجور بالمناطق الأقل تلوثا حيث يمثل ئل فئل

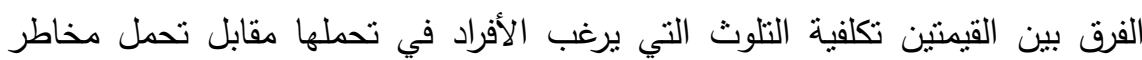
التلوث وما ينتج عنه من أضرار • r- مدخل القياس الكمي ذو المضمون الواحد: يقوم هذا المدخل على قياس الظواهر كميا

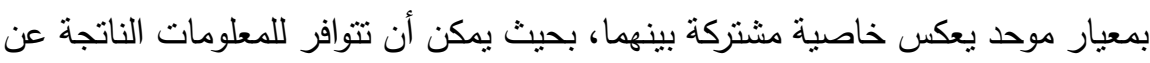

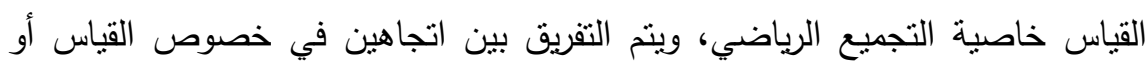
المضمون الواحد هما: 
القياس باستخدام وحدة المنفعة الاجتماعية الذي يعتمد على محاولة قياس درجة المنفعة أو الإثباع كميا في صورة وحدات منفعة نسمى وحدات المنفعة الاجتماعية.

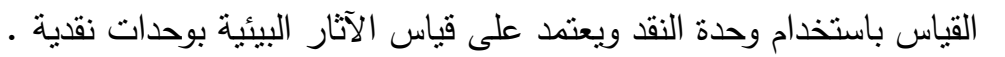
ع - مدخل القياس متعدد الأبعاد: يعتمد هذا المدخل عل قياس الظواهر بأساليب ومقاييس توفر وتبين خصائص هذه الظواهر ، ويتبع في ذلك أسلوبين هما:

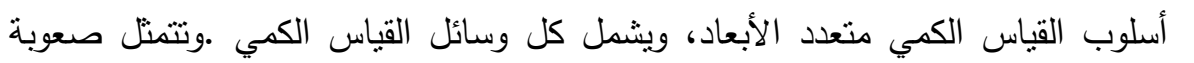
تطبيقيه في اختيار وحدة القياس المناسبة. أسلوب القياس الوصفي،ويقوم على وصف خصائص الحدث، بحيث بمكن لقارئ الحدث تصور هذه الخصائص أو المظاهر كما تتعكس على الثئ أو الحدث.

ه- مدخل التحليل المحاسبي العيني للعمليات البيئية: تهدف المحاسبة البيئية العينية إلى وصف العلاقة بين المجتمع والبيئة، ويقوم الهيكل العام لهذه المحاسبة على تتظيم مجموعة من الحسابات التي نذكر منها :حساب عنصر الهواء، حساب الطاقة البترولية وحسابات الطاقة الأخرى.

צ- مدخل دورة حياة المنتج لتحسين الأداء البيئي: من الإستراتيجيات المتبعة لتحسين الأداء

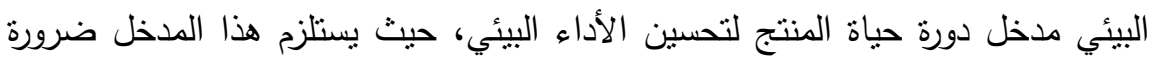

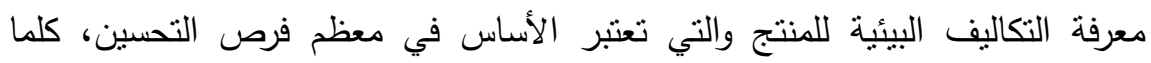
اكتسبت المنشأة الخبرة في تحديد هذه التكاليف زادت قدرتها على تحسين أدائها البيئي، وتكلفة دورة الحياة هي عملية تقدير التكاليف على مدى دورة حياة المنتج ككل، ومن المهم تحديد التكلفة في الصناعات التي تكون فيها تكاليف التخطيط والتطوير عالية أو تكاليف التخلص من المنتج مرتفعة.

V- النموذج البيئي المتوازن: يمثل النموذج البيئي المنوازن نتاج تفاعيل كل من المحاسبة الإدارية والإدارة البيئية بالمنشأة، حيث يسعى كلا النظامين نحو رفع درجة كفاءة استخدام

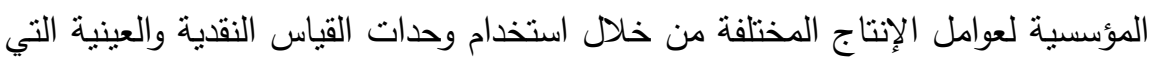
تمثل محاور النموذج البيئي المنوازن، ويتمنل هدف هذا النموذج في تحقيق رقابة وتقييم

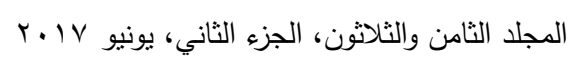


أداء المنشأة الصناعية على المستوبين الاقتصادي والبيئي، كما ويهدف في مقام ثان إلى توسيع دائرة اهتمام المحاسبين لكي تشمل الأمور البيئية، يعتمد النموذج البيئي على لى لئي

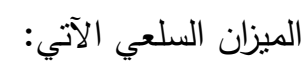

المدخلات + المنتجات تحت التشغيل = المخرجات + النفايات البيئية

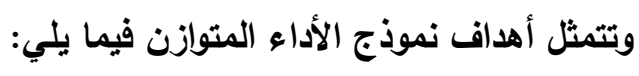

1-توجيه مسار المنشآت الصناعية نحو المساهمة الفعالة فى تحقيق التتمية المستدامة، وعدم

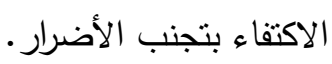

r-ترشيد تكاليف المنشآت الصناعية وقراراتها في كافة المجالات ذات الاتلات الآثار البيئية. r-القياس السليم لتكاليف المنتجات من خلال تخصيص التكاليف البيئية بطريقة علمية دقيقة. ع-رفع كفاءة إعداد التقارير الدورية الداخلية اللازمة لخدمة الإدارة.

ثانيا: أثر المحاسبة البيئية في تحسين جودة المعلومات: يلعب النظام المحاسبي دوراً في إمداد الإدارات المختلفة بالمعلومات المطلوبة للمساعدة في رسم السياسات واتخاذ القرارات، وعند اتخاذ قرار معين يتم دراسة جميع أبعاده، ومن أهم العوامل التي تؤنثر في عملية

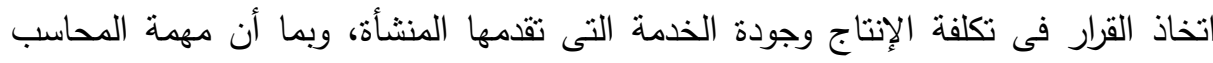
تكمن في تحديد وحصر جميع التكاليف المرتبطة بالنشاط أو الإنتاج، وهذا يؤدى إلى تحسين

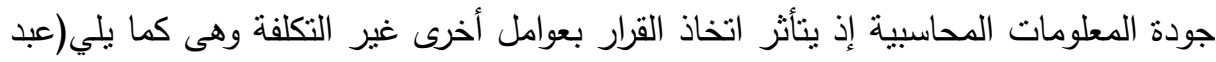

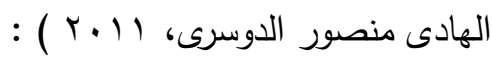

أولا: دور الاسترلتيحيات والنظم البيئة فحى اتخاذ القرارت: يشير الى أن عدد من الممارسات التي قامت بها المنشات الأمريكية لكسر الحواجز بين الأنشطة البيئية والعمليات اليومية واستراتيجيات اتخاذ القرار وتتضمن هذه الممارسات ما يلى : 1- تعيين مدير تتفيذي ينولى مسئولية القيام بالأنشطة البيئية .

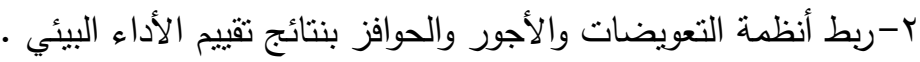
r- السماح بنشر التقارير المختلفة التي تصف الأنشطة البيئية . 
ع-قياس التكاليف والإيرادات البيئية والبحث عن الطرق المختلفة لتحويل النشاط البيئي الذى تقوم المنشأة الى قيمة مضافة لمصلحة المنشأة .

ثانياً: مقومات المعلومات المحاسبية البيئة: نقوم المحاسبة البيئية بأداء وظيفة نوفير المعلومات البيئية لكافة الإطراف المستفيدة والمستخدمة لها لمساعدتهم فى اتخاذ القرارات وتقييم اثر الأداء البيئي، وبالنالي فانه أصبح لهذه المعلومات أهمية كبيرة لاسيما المعلومات

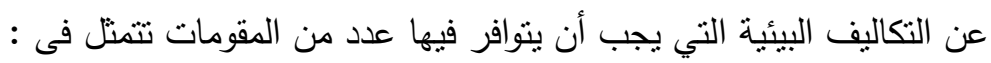
1- قدرة متخذ القرار على المفاضلة بين القرارات المختلفة.

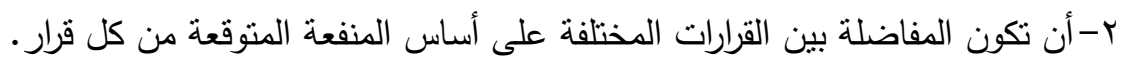

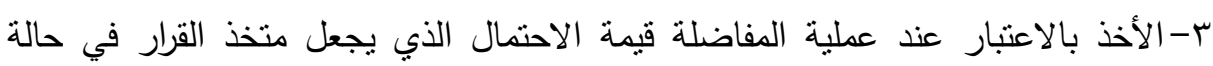
تغيير بين القرار الأول والقرارات الأخرى.

ثالثاً: ترتيب القرارات حسب منفعتها بالنسبة لمتخذ القرار: يوجد علاقة تبادلية بين التكاليف

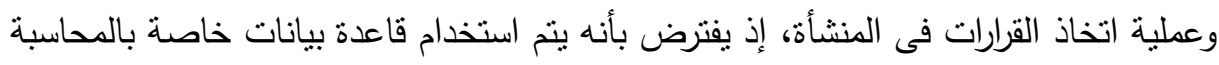

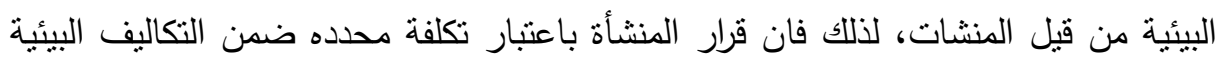

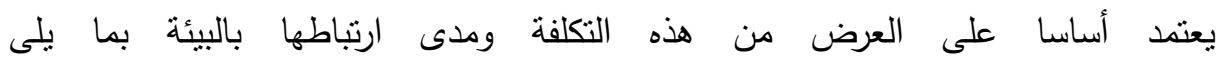
:(S.Toms,"Firm. 2012)

1. العناصر المهمة والحيوية للإدارة الجيدة للمشروعات وذللك من خلال قياس التكاليف البيئية ومدى تأثنرها المقاييس البيئية والإدارية المناسبة لهذه التكاليف التي تأخذ في اعتبارها مبدأ التكلفة والسبب. r. القياس الصحيح لقيمة الاستثمار وحجم التكاليف البيئية لتحديد أثز هذا الاستثمار على تحسين فعالية الأداء وبناء قرارات منطقية من خلال استخدام مؤشر العائد/ التكلفة.

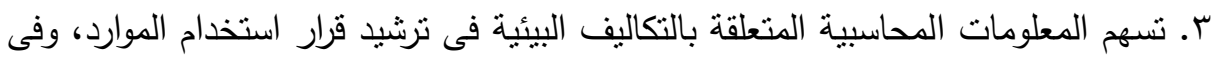

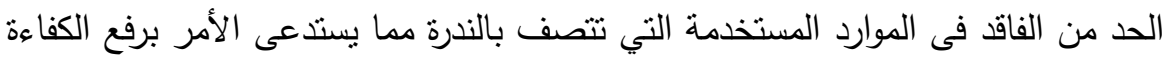
الفنية والاقتصادية للشركة . 
ع. القرارات المتعلقة بالتكاليف الخاصة بتخفيض وتقليص وإعادة تدوير المواد الخام

والمستهلكة.

ثالثا: أثر الإفصاح عن المعلومات البيئية على جودة التقارير المالية: إذا كان الهدف الأساسي من التقارير المالية هو إخلاء ذمة الإدارة قبل الملاك، ومن ثم انعكس الأمر

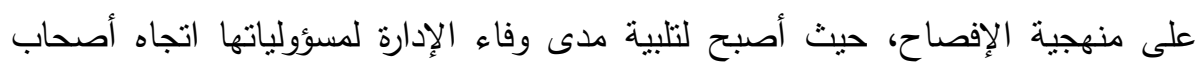

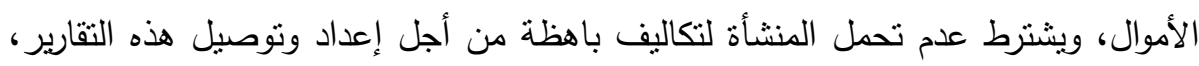

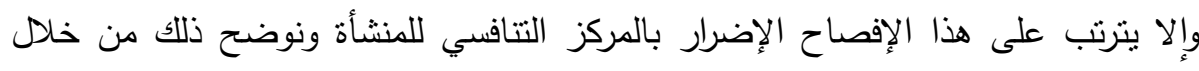
النقاط التالية:

1 - أهمية المعلومات البيئية المفصح عنها: أن السوق الكفء يستجيب لأي معلومات بمجرد الإفصاح عنها، وينعكس أثرها على أسعار الأوراق المالية، فجودة المعلومة البيئية

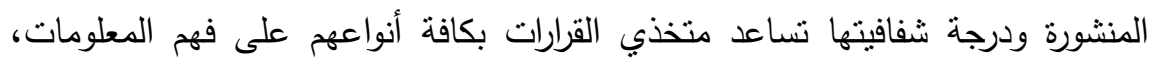
وتحليلها واستخلاص النتائج منها لتساعدهم في: تخفيض درجة فئس المخاطر من خلال الآتي:

(CHANG, H.C.,2013)

ا ـ التعرف على التأثيرات البيئية من القوائم المالية. r. القدرة على فهم المعلومات البيئية وأخذ نتائجها في الاعنبار عند استخدام أسلوب المفابه المفاضلة بين القرارات. r. تقليل درجة التباين في المعلومات البيئية المتاحة عن الأداء البيئي للمنشآت بعضها البعض. ع. تحقيق التكافؤ والعدالة بين المستثرين من خلال نوفير المعلومات البيئية المؤثرة عند عقد المقارنات. ه. عرض ونشر المعلومات البيئية المالية وغير المالية بالقوائم المالية وإيضاحاتها يلعب دورا مهما في عملية اتخاذ القرار الاستثماري لما تقدمه من نصح وإرشاد لتساعد المستثمرين. 
ب - تأثير الإفصاح عن الأداء البيئي على جودة التقارير المالية: بشمل مفهوم جودة التقارير المالية على مجموعة من خصائص المعلومات المالية التي تتضمنها تلك التقارير ، نتيجة

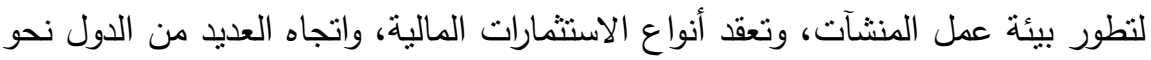

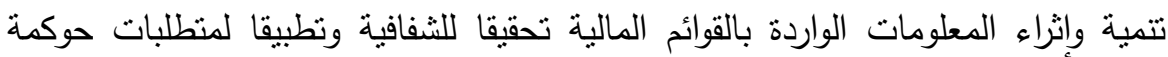

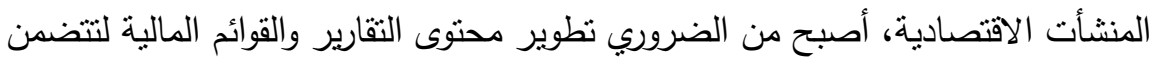
معلومات غير تقليدية تحقق الثفافية من جهة، وتدعم ثقة مستخدمي تلك التقارير من جهة

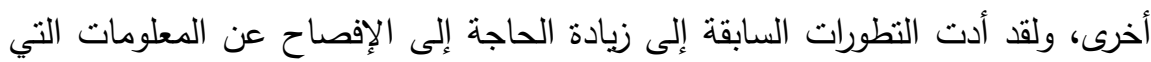

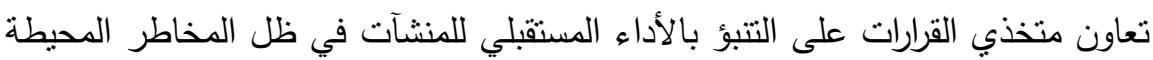

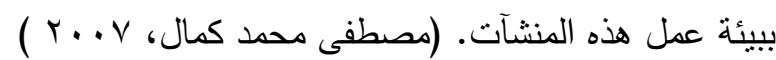
r- نماذج القياس والإفصاح عن المعلومات المحاسبية البيئية: 1-نموذجS: SMFC (SCOVIL MANUFACTURNING COMPANY استخدمتها شركة SCOVIL MANUFACTURNING للإفصاح عن أنشطتها الاجتماعية من النماذج التطبيقية الوصفية، الذي كان تحت عنوان" نقرير العميل الاجتماعي"، يتضمن التقرير بعض المعلومات الكمية عن فرض التوظيف التي هيأتها

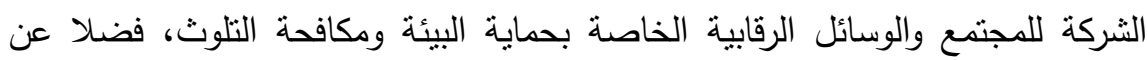

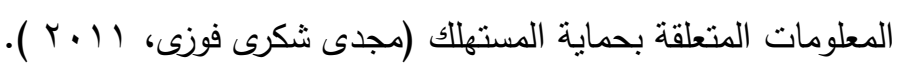
r-نموذج (Linowes): يهنم هذا النموذج الذي اقترحته Linowes وأطلق عليه نسمية

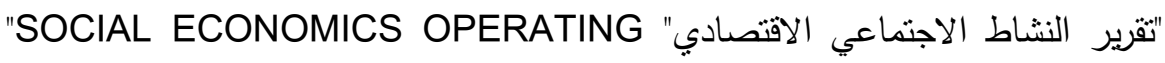
بالإفصاح عن التكاليف المترتبة على كل نشاط من أنشطة المسؤولية الاجتماعية منها

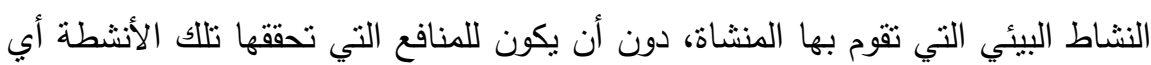
أثز فيها r-نموذ (Estes) ]ـ لا يختلف النموذج الذي اقترحه Estes و أطلق عليه نسمية" نقرير

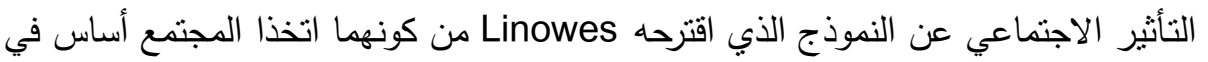
الإفصاح عن الأنشطة الاجتماعية للمنشاة، إلا أن الاختلاف الذي ميز هذا النموذج عن

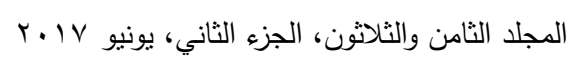


سابقه يكمن في اهتمامه بالمنافع الاجتماعية إلي جانب التكاليف الاجتماعية، ومحاولة قياس

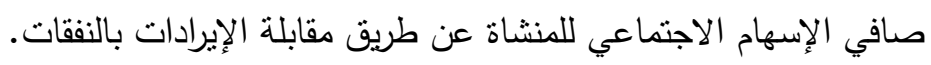

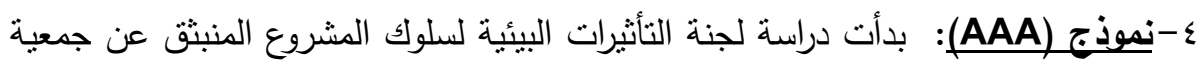

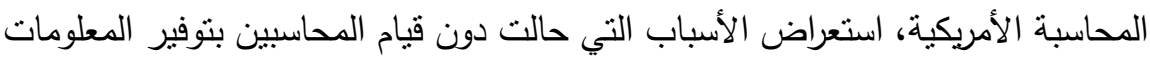

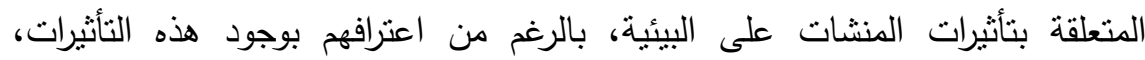
فأوضحت بأنه لا توجد أسس وقواعد لقياس وعرض التكاليف الاجتماعية للأضرار البيئية الناجمة عن عمليات المنشات

ه-نماذج التقرير عن المسؤولية البيئية: يعد اختيار المعلومات التي تعبير عين الأداء

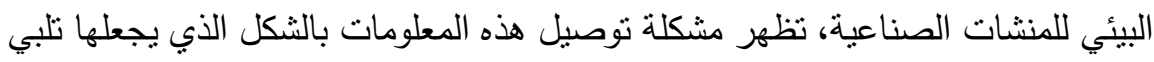

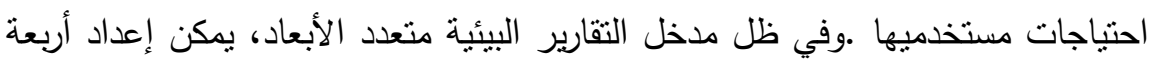
نماذج أساسية للتقرير عن المسؤولية البيئية للمنشات الصناعية بحيث تلحق في جزء لكئه

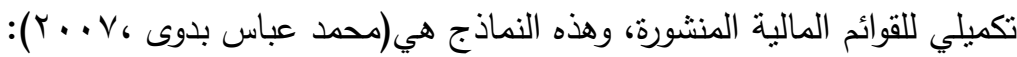

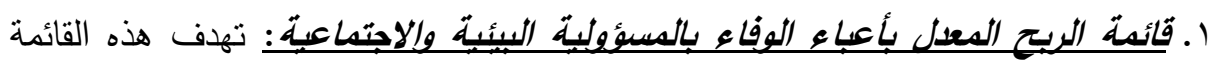

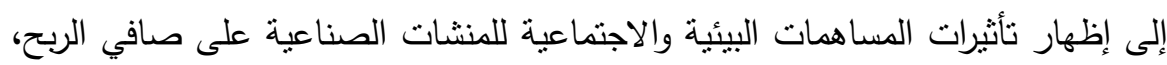
سواء كان أثز هذه المساهمات مفروض بقرارات سيادية أو بطريقة اختيارية.

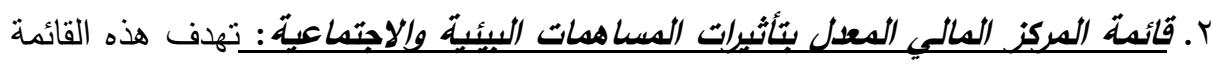

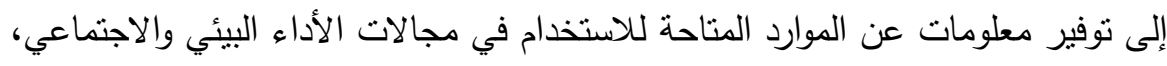
وما يقابلها من حقوق للغير، ويفيد هذا النموذج في التعرف علي عناصر الثروة التي ينتج

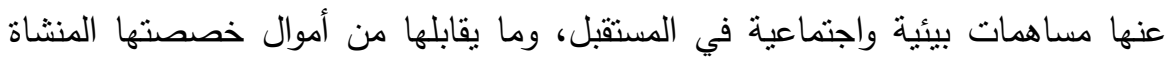
لامتلاكها.

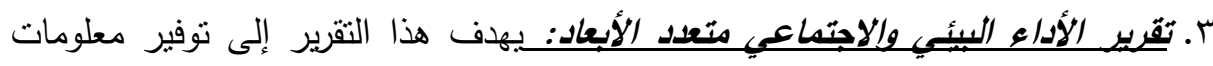

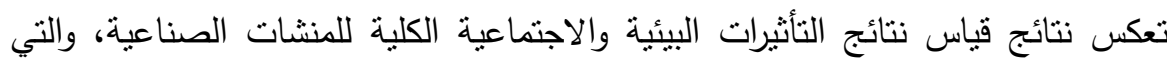
أعتمد في قياسيها على أدنى مدخل القياس متعدد الأبعاد. 
ع. القائعة المالبة لتأثيرات عدم الوفاء بالمسئولية البيئية والاجتماعية: تهـف القائمة المالية لتأثثرات عدم الوفاء بالمسؤولية البيئية والاجتماعية إلى نوفير معلومات تعكس نتائج القياس النقدي للعمليات البيئية والاجتماعية المؤدية إلى انحرافات غير ملائمة في الأداء

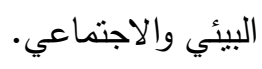
يرى الباحث أن جميع هذه النماذج السابقة بمداخلها وأنواعها ومجالاتها والتعبير

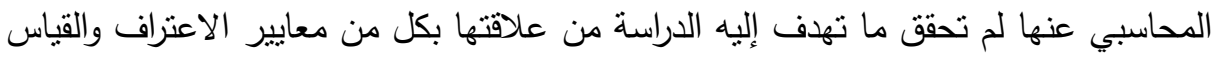

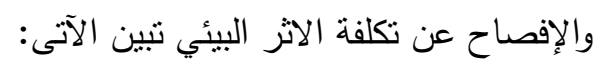

1 . عدم وضوح معايير السياسة البيئية فى النماذج حيث انها ضئ الئن السياسية الاجتماعية. r. اعتمدت على التكلفة الاختيارية وليست الإجبارية. r. القياس وفقا لهذه النماذج لتكلفة الاداء البيئي غير دقيق حيث الإحيانه أنها اكتفت بنوع واحد فقط

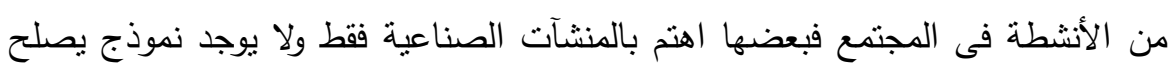
لقياس تكلفة الاداء البيئى بصفة عامة مع إمكانية التطبيق فى قطاع المقاولات.

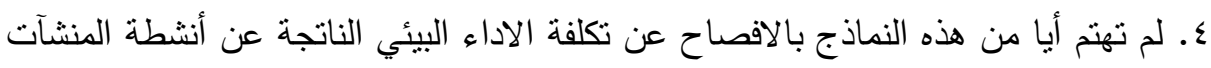

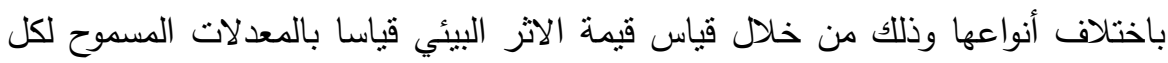
مسبب من مسببات النلوث وذللك لتحسين جودة المعلومات لتحقيق ميزة تتافسية للمنشات.

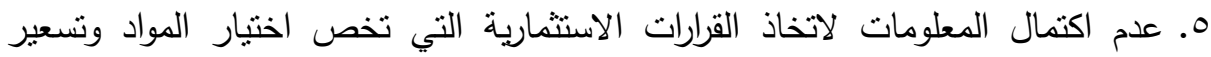

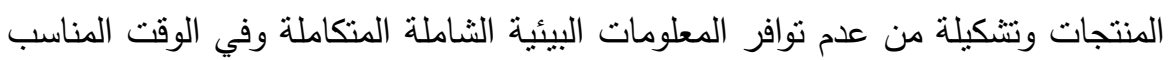
،بالرغم من أهمبة هذه القرارات المستقبلية التي تشكل تحديات محددة لأوضاع غواع غير مؤكدة. رابعاً: الاراسة التطبيقية: اعتمد الباحث فى جمع بيانات الدراسة التطبيقية على قائمة استقصاء، نم إعدادها بطريقة تحقق أغراض البحث وتختبر فروضه من خلا توصيف باسفال مجتمع وعينة الدراسة. أداة الاراسة: قام الباحث بتصميم قائمة استقصاء من (VT) فقرة وذلك لقياس متغيرات الدراسة لاعداد نموذج لاستخدام المحاسبة عن الاثر البيئي فى تحسين جودة المعلومات بقطاع الهاع

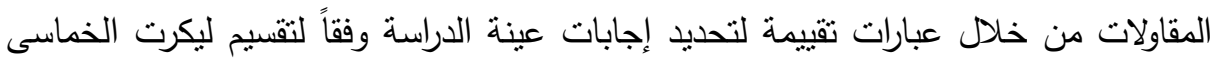

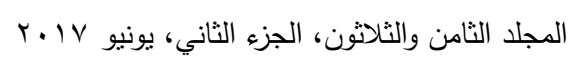


(غير مهم جداً، غير مهم، منوسط الاهمية، مهم، مهم جداً). وتم استثارة ذوي الخبرة في هذا المجال في الحقل الأكاديمي والمهني. توصيف متغيرات الدراسة: نم تصميم استمارة الاستقصاء في شكل عشره أسئلة يمكن إيضاحها فيما يلي: • المتغير الأول (Q1): ويمثلك السؤال الأول والذي يظهر مدى اهتمام المنشات بقطاع المقاولات بالأثر البيئي. • المتفير الثاني (Q2): ويمثلك السؤال الثاني حول وجود نظام محاسبي مطبق لدى المنشأة بسمح لها بقياس تكاليف تأثنير أنشطتها على البيئة المحيطة.

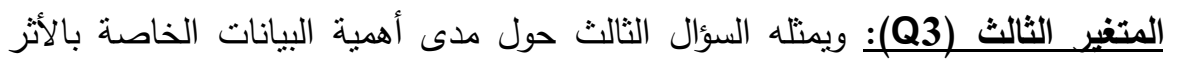
البيئي لكل إدارة فى المنشات بقطاع المقاولات. • المتفير الرابعــ(Q4): ويمنله السؤال الرابع الذي يظهر مدى أهمية تأثنير قياس وتحليل الأثر البيئي على جودة المعلومات المحاسبية بالمنشأة.

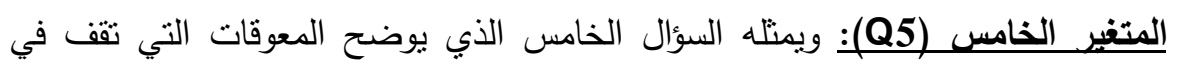
تطبيق عملية القياس والإفصاح عن تكاليف الأثر البيئي في القوائم المالية للمنشات بقطاع المقاولات. • المتفير السادس (Q6): ويمنلك السؤال السادس الذي يحدد العوامل المطلوبة لتطبيق عملية القياس والإفصاح المحاسبي عن الأثر البيئي التي يمكن الاعتماد عليه في اتخاذ القرارات بالمنشات بقطاع المقاولات. • المتغير السابع (Q7): ويمثلك السؤال السابع الذي يوضح أثر استخدام القياس والإفصاح المحاسبي الأداء البيئي في تحسين جودة المعلومات لدى متخذي القرارات في المنشات بقطاع المقاولات. ه المتغر الثامن (Q8): ويمثلك السؤال الثامن الذي يظهر مدى استخدام المعلومات عن الأثر البيئي من قبل الإدارة العليا عند اتخاذهم القرارات الإدارية. 
• المتغبر التاسع (Q9) :ويمثله السؤال التاسع الذي يظهر مدى استخدام الإفصاح المحاسبي عن تكاليف الأثر البيئي في الثقارير المالية إلى نرشيد القرارات لدى الإدارة العليا بالمنشأة.

إنعاشر(Q10): ويمنلك السؤال العاشر الذي يظهر مساهمة الإفصاح المحاسبي عن تكاليف الأثز البيئي فى تحقيق ميزه تتافسية للمنشات في قطاع المقاولات ثبات أداة الدراسة: للتأكد من الثبات، اعتمد الباحث على طئى طريقة الاتساق الداخلي باستخدام معادلة كرونباخ ألفا (Consistency) الثبات كما يلي:

جدول( ) : قيمة معاملات الثبات كرونباخ ألفا (Cronbach Alpha) لمتغيرات الدراسة

\begin{tabular}{|c|c|c|c|}
\hline كرونباخ & الفقرات & 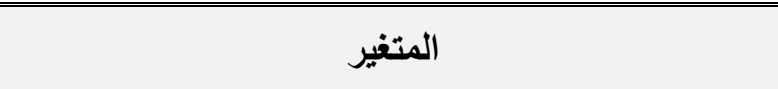 & المتغير \\
\hline $.67 \leq V$ & 1. & مدى إهتمام الإدارة العليا بالآثر البيئي & Q1 \\
\hline .6091 & 9 & 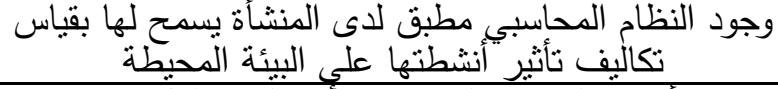 & Q2 \\
\hline .6710 & $\varepsilon$ & مدى أهمية البيانات الخاصة بالآثر البيئي لكل إدارة فى المقات المقات & Q3 \\
\hline .6079 & V & 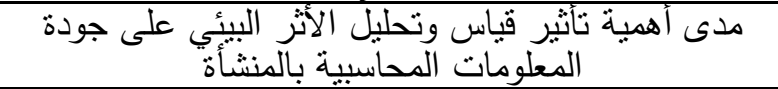 & Q4 \\
\hline $.6 V \leqslant 1$ & ir & 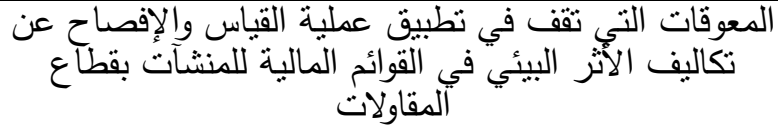 & Q5 \\
\hline $.00 \leqslant 0$ & $\mathrm{~V}$ & لعوامل المطلوبة لتطبيق عملية القياس والإفصاح المحاسبي & Q6 \\
\hline $.6 \vee 94$ & $\Lambda$ & 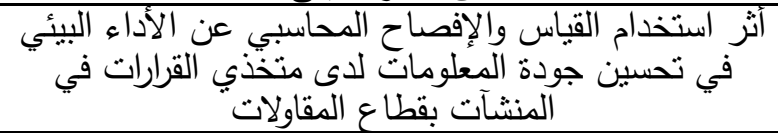 & Q7 \\
\hline . 6V & 0 & مدى استخدام المعلومات عن التخاذهم القرارات البيئي من قبل الإدية الإدارة & Q8 \\
\hline ס & 0 & 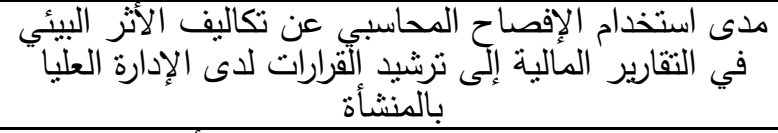 & Q9 \\
\hline .6110 & 7 & 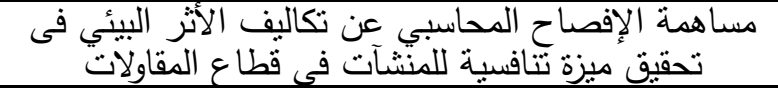 & Q10 \\
\hline $.6 V) \varepsilon$ & $V \mu$ & المعدل العام للثبات & \\
\hline
\end{tabular}

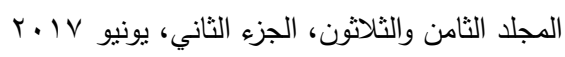


v. ) يظهر من الجدول إن جميع المجالات حصلت على قيمة كرونباخ ألفا اكبر من \%) وهذا يدل على جميع مجالات الدراسة مقبولة لأغراض البحث العلمي في مثل هذه البحوث.

\section{حدود الدراسة: يمكن تلخيصها كما يلي:} زمنيا: تم إجراء الدراسة ابتداء من شهر مارس من عام ألفان وستة عشرة إلى غاية شهر

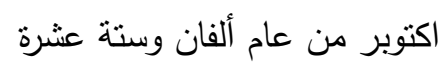
مكانبا: أجريت الدراسة الحالية على ثمانية وثلاثون شركة بقطاع المقاولات كما يلى:

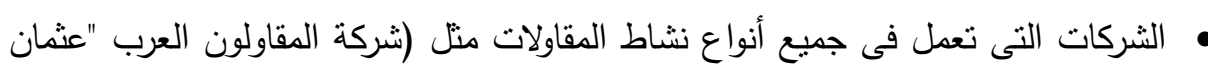
احمد عثمان"، شركة المقاولات المصرية "مختار إبراهيم"، شركة النصر العامة للمقاولات لهنات

الشركات المتخصصة التى تعمل فى نوع من أنواع نشاط المقاولات مثل شركات للأعمال

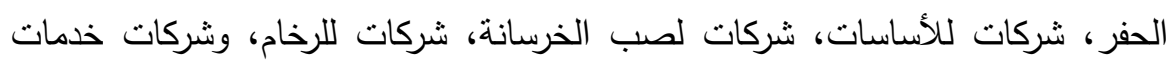

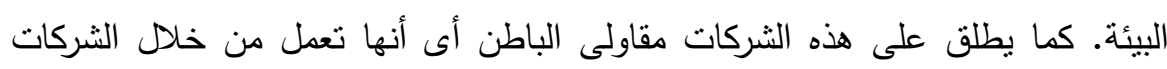
التى تعمل فى جميع أنواع نشاط المقاولات. توصيف مجتمع الاراسة: يتمثل مجتمع الدراسة فى القائمين على اتخاذ القرار بالادارة التنفيذية

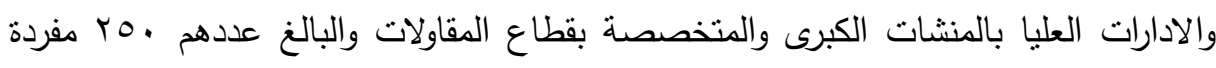

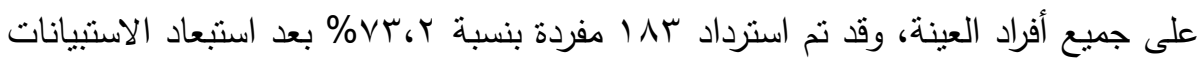

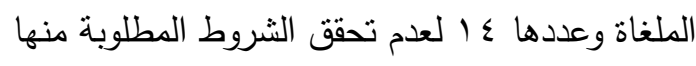
أسلوب اختيار العينة: نم عرض هذه الاسئلة على العاملين بشركات المقاولات ذو مستويات

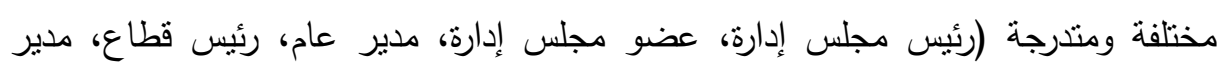

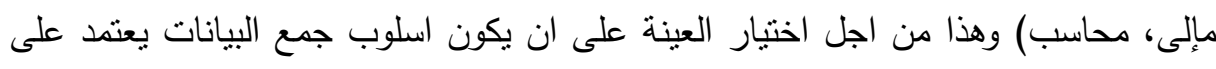

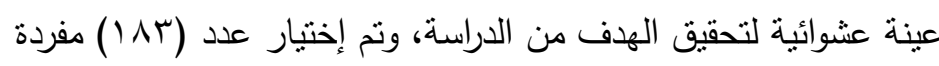


التحليل الاحصائى للفروض: قام الباحث باستخدام الاساليب الاحصائية التالية :

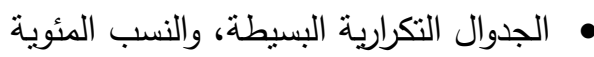

• المقاييس الوصفية كالوسط الحسابى، والانحراف المعيارى، والتباين، والارتباط • عند اختبار الفرض الاول، يتم من خلال نتائج اجابات الاسئلة الاول والثانى والثالث ولائل

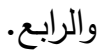
• عند اختبار الفرض الثانى، يتم من خلال نتائج اجابات الاسئلة الخامس والسادس والسابع.

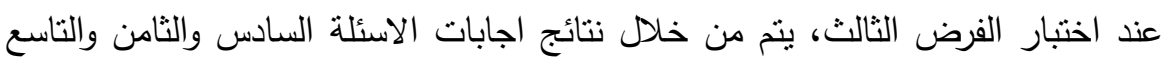
والعاشر

نتائج التحليل الاحصائى: نوصل الباحث الى المتغيرات المستقلة التى تؤثر على استخدام القياس والإفصاح المحاسبي الأداء البيئي في تحسين جودة المعلومات لاعى متخذي القرارات ومدى مساهمة الإفصاح المحاسبي عن تكاليف الأثر البيئي فى تحقيق ميزه تتافسية للمنشات

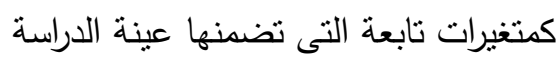

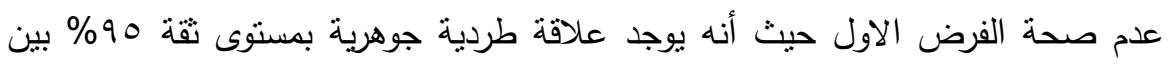
الاعنماد على المعايير المحاسبية في ضوء الأبعاد البيئية المؤثرة عند إعداد القوائم المالية

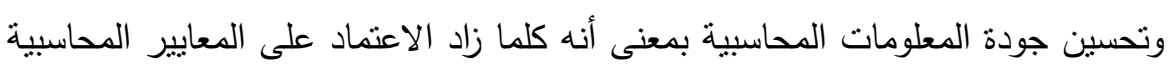

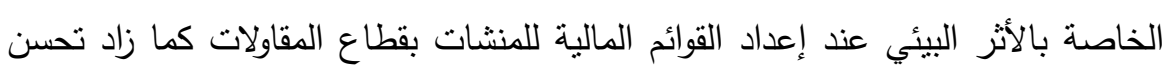

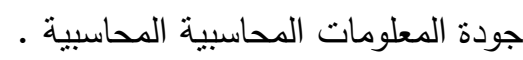
أثنتت الدراسة عدم صحة الفرض الثانى لان هناك علاتهة طردات طردية جوهرية بمستوى ثقة 90 بين المعوقات والعوامل المطلوبة لتطبيق القياس والإفصاح عن أثز الأداء البيئي فى القوائم المالية لدى منشات قطاع المقاولات وأثز استخدام القياس والإفصاح في تحسين جودة المعلومات. • أثتتت الدراسة عدم صحة الفرض الثالث لان هناك علاقة طردية جوهرية بمستوى ثقة 9\% بين بين عملية قياس ومعالجة بيانات تكاليف الأثر البيئي ومساهمة الإفصاح المحاسبي فى تحقيق ميزه تتافسية للمنشات في قطاع المقاولات.

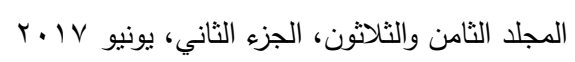


• قام الباحث بعمل تحليل انحدار لعينة الدراسة على الفرض الاول الحصول على المعادلة

جدول(ץ): معاملات الانحدار بين الاعتماد على المعايير المحاسبية في ضوء الأبعاد البيئية

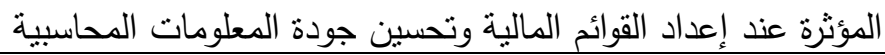

\begin{tabular}{|c|c|c|c|c|c|}
\hline الالالة & القيمة الاحتمالية & قيمة & الخطاً المعيارى & المعاملات & بيان \\
\hline معنوى & $\overline{\cdot, \ldots}, \ldots$ & $1 \mu_{6} \mu^{\prime}$ & .6511 & $Y_{\text {(ANY }}$ & الجزء التابت \\
\hline معنوى & $\cdot, \ldots$ & $\varepsilon_{6} \vee V 7 \Lambda$ & .6 .07 & $.6 Y 70$ & Q3 \\
\hline
\end{tabular}

$\mathrm{Q} 4=2.821+0.265 \mathrm{Q} 3$

• كما أظهرت نتائج تحليل الانحدار لعينة الدراسة على الفرض الثانى الحصول على

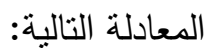

جدول(ץ): معاملات الانحدار بين نأثير المعوقات والعوامل المطلوبة لنطبيق القياس والإفصاح عن

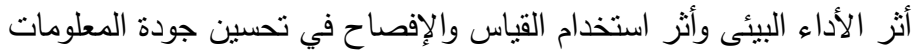

\begin{tabular}{|c|c|c|c|c|c|}
\hline الدلالة & القيمة الاحتمالية & قيمة t قيمة & الخطا المعيارى & المعاملات & بيان \\
\hline معنوى & $\cdot, \cdots$ & E6V77 & .619 & 1.04. & الجزء الثابت \\
\hline معنوى & $\cdot, \cdot 10$ & $r_{6} \leqslant 7 \leqslant$ & .6 .10 & .64 .9 & Q5 \\
\hline معنوى & $\cdot, \cdots$ & $0,5.0$ & $\cdot 6 \cdot \lambda V$ & $\cdot 6 \leqslant V 1$ & Q6 \\
\hline
\end{tabular}

المصدر: من إعداد الباحث

$\mathrm{Q} 7=1.520+0.209 \mathrm{Q} 5+0.471 \mathrm{Q} 6$

• كما اظهرت نتائج تحليل الاتحدار لعينة الدراسة على الفرض الثالث الحصول على

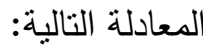

جدول(؛): معاملات الانحدار بين نأثثر العوامل المطلوبة لتطبيق عملية القياس والإفصاح واستخدام

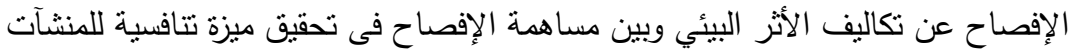

\begin{tabular}{|c|c|c|c|c|c|}
\hline الالالة & القيمة الاحتمالية & قيمة & الخطألمعيارى & المعاملات & بيان \\
\hline غلر معنوى &.,$V \Psi \leqslant$ & $(\cdot, r \leqslant \cdot)$ & $.6 r \mathrm{NV}$ & $(\cdot .61 \pi)$ & الحزء الثابت \\
\hline معنوى & $\cdot, \cdots$ & $r .7 .1$ & .6 .91 & $.6 Y Y V$ & Q6 \\
\hline معنوى & $\cdot, \ldots$ & $\Lambda_{6} Y \wedge T$ & .6 .19 & $.670 Y$ & Q9 \\
\hline
\end{tabular}

المصدر: من إعداد الباحث

$Q 10=(0.131)+0.327 Q 6+0.652 Q 9$ 


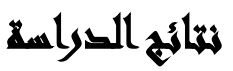

ا. أن دوافع بعض المنشات بقطاع المقاولات للاهتمام بالأثر البيئي يرجع إلى التزام المنشأة

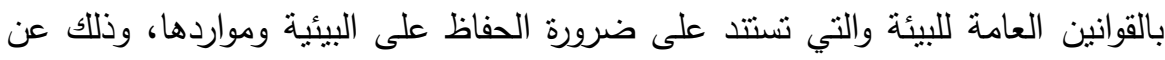

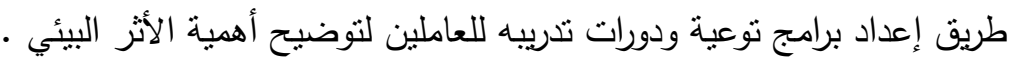

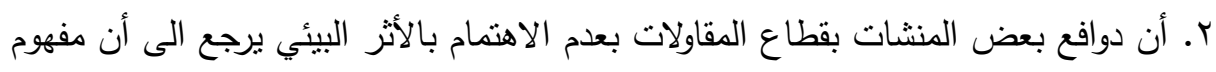

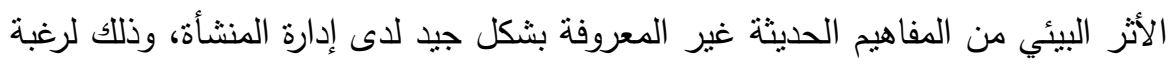
الإدارة العليا في المنشآت بقطاع المقاولات في التميز التجاري وعدم تحمل تكاليف إضافية. r. أهم الأسباب التي تدفع المنشات بقطاع المقاولات بوجود نظام محاسبي مطبق لديها يسمح

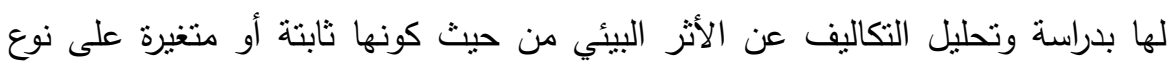

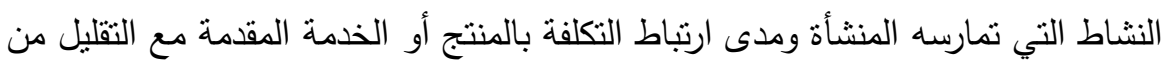
الالتزام (التعويضات والغرامات ) التي قد تتشأ بسبب عدم الالتزام المنشأة بقانون حماية البيئة.

ع. يؤثز قباس وتحليل الأثر البيئي على جودة المعلومات المحاسبية بالإيجاب على سمعته المنشأة وذللك لتحسين عملية التخطيط البيئي للمشاريع المستقبلية. 0. أن أهم المعوقات التي تقف في تطبيق عملية القياس والإفصاح عن تكاليف الأثر البيئي

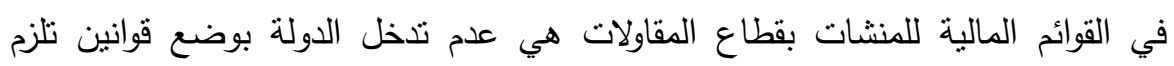

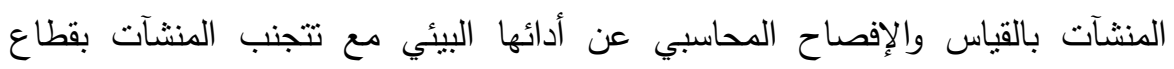
المقاولات الإفصاح عن المعلومات البيئية التي من الممكن أن بيتقيد منها المنافسون

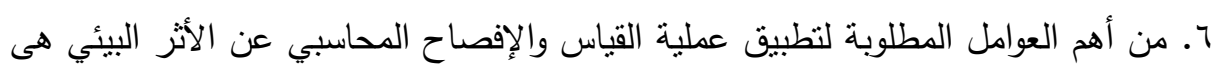

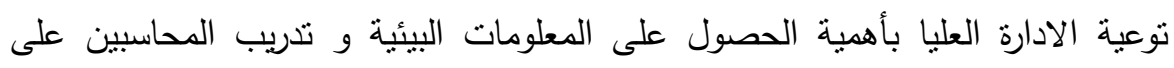
معايير المحاسبة المتعلقة بالبيئة 
V. أن استخدام القياس والإفصاح المحاسبي عن الأداء البيئي في تحسين جودة المعلومات

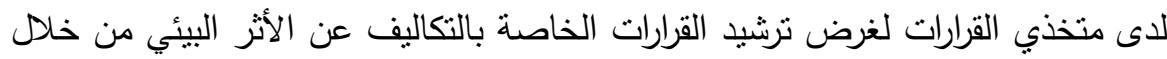
المعلومات التي تشاعد في عملية الرقابة والتحكم في كافة مصادر التلوث بالمنشأة.

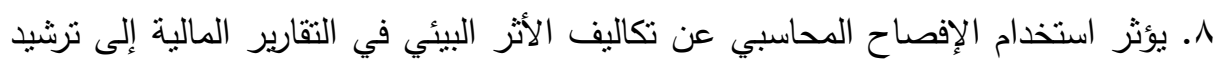
القرارات لدى الإدارة العليا بالمنشأة على قرار قبول أو رفض الإحن الدراسات الجدوى الاقتصادية

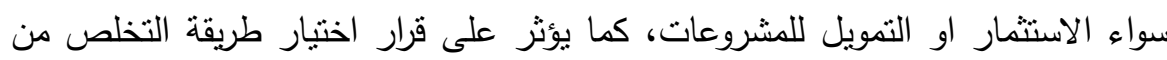
النفايات.

9. أن مساهمة الإفصاح المحاسبي عن تكاليف الأثر البيئي لتحقيق ميزه تتافسية للمنشات في

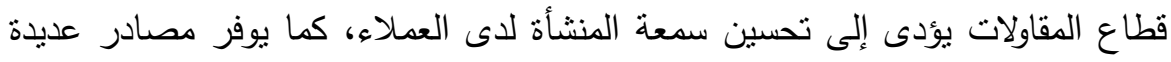
للمنشأة لحصول على التمويل اللازم للمشروعات المراد تتفيذها.

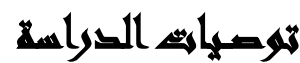

ا. العمل على نشر الوعي عن أهمية الأثز البيئي للى جميع الأطراف المهتمة سواء للمجتمعات أو المسئولين أو المنشآت والعاملين فيها خاصة المديرين والمحاسبين. r. ضرورة تكامل السياسة التظيمية للمنشأة مع السياسات المحاسبية فى عملية تحليل عناصر تكاليف الأداء البيئي، وتبوبيها وعلاقتها بدورة النشاط لدى المنشأة، كما سيظهر دور عملية القياس المحاسبي من خلال البيانات والمعلومات البيئية الكمية والنوعية

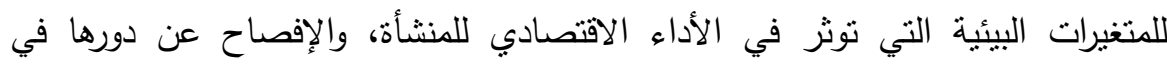
المحافظة على البيئية وتخفيض الأثر البيئي السلبي لنشاط المنشأة البهاه

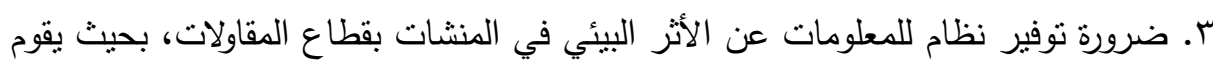
هذا النظام بتوفير المعلومات اللازمة لإعداد وتتفيذ وتقييم الخطط البيئية ويوفر معلومات الترئ

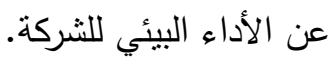


ع. ضرورة اعتبار الأثر البيئي للمنشأة أحد العوامل الهامة في تقييم أدائها باعتبار أن تحسين الأثر البيئي يؤثز بشكل جوهري على باقي جوانب الأداء المتوازن الأخرى للمنشأة ( المالي

$$
\text { والإداري والتسويقي والتحسين الاخلي والنمو ). }
$$

ه. ضرورة استحداث قسم للمحاسبة البيئية داخل الإدارة المالية للمنشأة يتابع الأداء البيئي

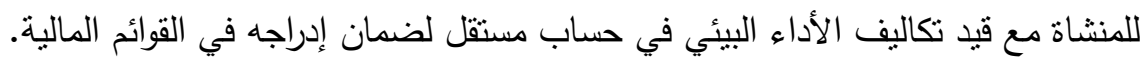
T. على المنشات بقطاع المقاولات الإفصاح عن تكاليف الأثر البيئي في تقاريرها المالية لترشيد قرارات الأطراف ذات العلاقة، حيث أن إمداد متخذي قرارات الاستثمار بالمعلومات

البيئية بجعلها يستثرون أموالهم في المنشات ذات الكفاءة العالية في مكافحة التلوث. V. فرض سياسة ضريبية معينة من قبل الدولة على المنثات بقطاع المقاولات التي لا تلتزم بمسؤولياتها البيئية، بحيث تشكل حافزاً لتخفيف التلوث، وأن تكون هذه الضربية لهنية مرنه، بحيث تشجع على الالتزام بالمسؤولية البيئية والإفصاح عنها في القوائم المالية، وإلزام المراجعين الخارجيين بمراجعة الأداء البيئي للمنشأة.

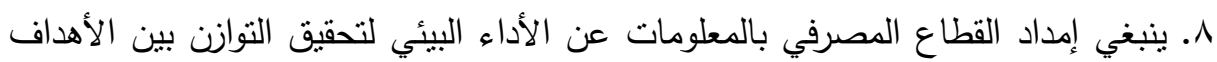
لالبيئية عند اتخاذ القرارات بمنح القروض للمنشات بقطاع المقاولات وذللك من خلال إلزام المنشات بتوسع فى نطاق الإفصاح المحاسبي ليشمل الثقارير المالية معايير الإفصاح عن تكاليف الأداء البيئي في التقارير المالية السنوية.

\section{المرايع}

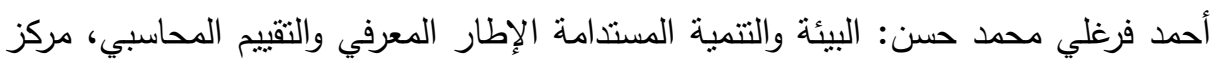

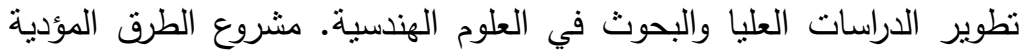

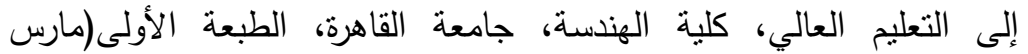
(r...

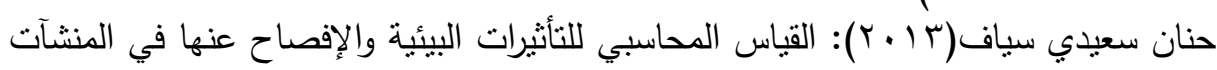

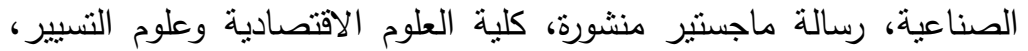
جامعة قسنطينة.

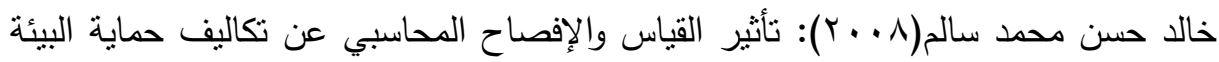
على قرار الاستثمار ، رسالة ماجستير ، كلية التجارة جامعة عين شمس.

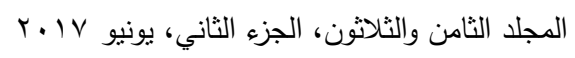


طه عليوي ناصر : هيثم هاشم الخفاش،"أهمية القياس المحاسبي للتكاليف البيئية ودورها في

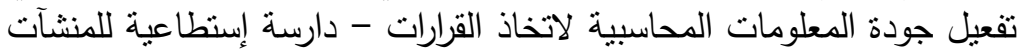

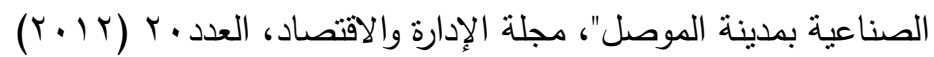

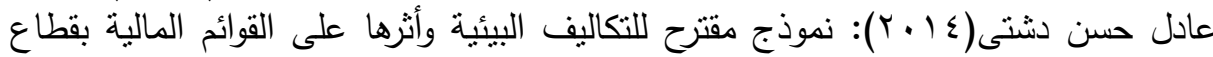

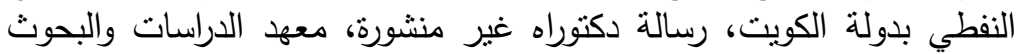

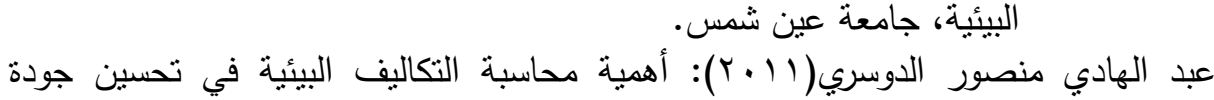

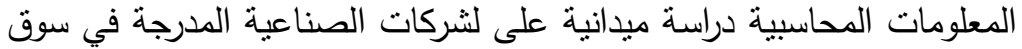

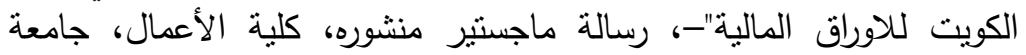
الشرق الأوسط.

عز الدين فكرى تهامى:الإطار العلمي لنظم محاسبة الإدارة البيئية، المجلة العلمية لكلية

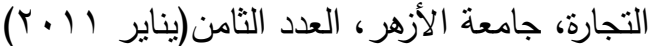

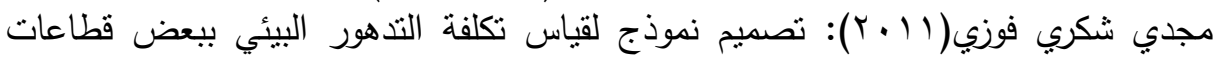
التشييد والبناء، رسالة دكتوراه غير منشورة، معهد الدراسات والبحوث البيأئية،

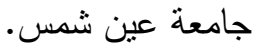

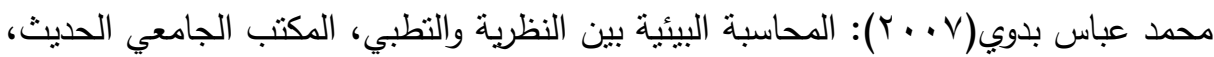

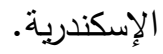

مصطفى محمد كمال محمد حسن: القياس والإفصاح المحاسبي عن مخاطر المنظمات -

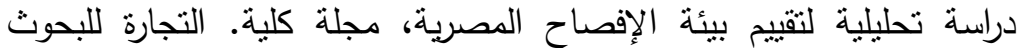

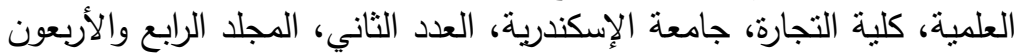
r...V

مهاوات لعبيدى(10 • Y): القياس المحاسبي للتكاليف البيئية والإفصاح عنها في القوائم المالية

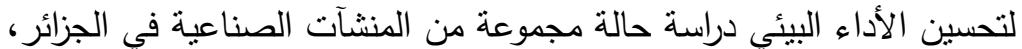

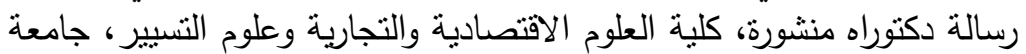
محمد خضير بسكره.

CHANG, H.C(2013): Environmental management accounting in the Taiwanese top education sector Issues and opportunities, International Journal of Sustainability in Top Education, Vol. 14 No.2.

Expert working group," Environmental Management Accounting Procedure and Principles", United Nation, New York, 2009. 
Graciela Marı'a Scavone(2006): Challenges in internal environmental management reporting in Argentina, Argentina Sustentable A.C., Buenos Aires, Argentina.

Kitzman k. (2010): Environmental Cost Accounting For Accounting For Improver Environmental Decision Making Pollution Engineering.

JAIKUMAR, G., KARPAGAM, M. (June 2013): and THIYAGARAJAN, S., Factors Influencing Corporate environmental Performance in India, Indian Journal of Corporate Governance, Volume 6, No 1, January-.

Omneya H.Abdeslam,pouline weetman,(2007): " Measuring Accounting Disclosure in a period of complexchanges :The case of Egypt Review Article",Advance international accounting, vol 20.

Muttanachai Suttipun, Patricia Stanton(2012): Determinants of environmental disclosure in Thai corporate annual Reports, International Journal of Accounting and Financial Reporting, ISSN 2162-3082, Vol.1, No.1

S.Toms,(September 2012): "Firm Resources, Quality Signals and The Delterminants Of Corporate Environmental Reputation :Some UK Evidence", The British Accounting Review,Vol. 34,Issue.3.

Teresa Cristina Pereira Eugénio(April 2009): Social and environmental accounting :Acase study on a portuguse cement company, Thesis submitted as partial requirement for the conferral of PHD in Management, specialization in Accounting.

Issues in Accounting Education.

http://accounting.rutgers.edu/raw/aaa/pubs/issues.htm

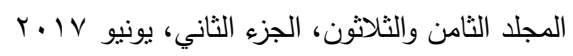




\title{
A PROPOSED MODEL FOR USING THE ACCOUNTING OF THE ENVIRONMENTAL IMPACT IN IMPROVING INFORMATION QUALITY IN CONTRACTING SECTOR - AN APPLIED STUDY
}

Khalifa, M. A. ${ }^{(1)}$; El-Shahaat, T. M. ${ }^{(1)}$ and Abdel Sadek, A. M. ${ }^{(2)}$ 1) Faculty of Commerce, Ain Shams University 2) The Arab Contractors (Osman Ahmed Osman \& Co)

\begin{abstract}
This study aims to Preparation a model for the use of the accounting for the environmental impact to improve the quality of information when making the top management decisions contracting sector, which achieves efficient environmental impact assessment costs in order to be disclosed in the financial reports, and so the problem of the research is the lack of understanding and awareness on the part of the top management installations, construction sector, the importance of the application of the measurement and disclosure of accounting for environmental performance in the financial statements to improve the quality of information, and what are the obstacles that prevent the enterprises in the measurement and disclosure of environmental costs to improve the quality of information on the environmental impact in the construction sector companies.

The study examined the concept of accounting for the environmental impact as selection variables, standards and procedures for the process to measure the environmental impact of the facility and the impact of environmental performance on the quality of information provided to the top management on the decisions they make plans for the development of future costs.
\end{abstract}


محمد عبد العزيز خليفة وآخرون

The researcher depends on deductive approach based primarily on the development of information derived directly from the references and research and previous studies as well as scientific journals and periodicals on the subject, it has also been compiling data on the study through questionnaires distributed to companies in the construction sector.

The researcher reached several conclusions, including the attention span of facilities sector contracting the environmental impact, and the extent of the accounting system applied to the entity's ability to measure the environmental impact resultin $7 \mathrm{~g}$ from the facility on the surrounding environment, the activities of the costs, and the importance of the effect of the measurement and analysis of the environmental impact on the quality of accounting information facility, with the knowledge of the obstacles that stand in the application of the measurement and disclosure of environmental impact in the financial statements of the companies construction sector costs.

$$
\text { المجلد الثامن والثلاثون، الجزء الثاني، يونيو Y Y r Y }
$$

